\title{
LA ALIMENTACIÓN EN AL-ANDALUS A PARTIR DEL REGISTRO ARQUEOFAUNÍSTICO. ESTADO DE LA CUESTIÓN*
}

THE FOOD IN AL-ANDALUS FROM THE ARCHAEOFAUNISTIC REGISTRY. STATE OF THE ISSUE

Recepción: 04-03-2017

Aceptación: 28-07-2017

DESIDERIO VAQUERIZO GIL

Universidad de Córdoba

dvaquerizo@uco.es

http://orcid.org/0000-0002-8604-958X

\section{Resumen}

Al-Andalus fue un espacio plural, dinámico y variable en el tiempo, que bebió de influencias culturales muy diversas. Todo ello le dio una idiosincrasia mestiza y claramente mediterránea que sólo consiguieron matizar la religión y sus rigurosas prescripciones, también en el campo de la alimentación. Aun así, y con sólo ligeros matices que evolucionan, cambian o se enriquecen a lo largo de los siglos conforme evoluciona también el propio alAndalus, los andalusíes practicaron un modo de comer sano y socializador, nutrido de alimentos que combinaron de forma hábil y sabia incluso en sus expresiones más pobres y frugales -dirigidos de alguna manera por sus sabios y dietistas, herederos militantes de los legados grecorromano y oriental-, pero también de manera intuitiva y espontánea. Tales prácticas se vieron favorecidas por un nuevo sistema de explotación de las tierras, basado fundamentalmente en la irrigación, la introducción de nuevas especies vegetales y una intensificación racional de las cosechas que les permitieron disponer de productos frescos todo el año, protagonistas sin saberlo de lo que muchos autores han dado en llamar la revolución verde. De todo ello dan buena cuenta las fuentes escritas, pero también la arqueología, en particular el registro faunístico; de ahí la necesidad de cruzarlos, en aras de contrastar ambos universos.

Palabras clave. Al-Andalus; alimentación; dieta mediterránea; irrigación; revolución verde; cocina; medicina; sabiduría popular.

\begin{abstract}
Al-Andalus was a plural and dynamic area, as well as variable timewise, drawing on very diverse cultural influences. This led to its hybrid and clearly Mediterranean idiosyncrasy that only religion and its strict requirements managed to tinge, including the field of food. Even so, and with only slight nuances that evolve, change or enrich down the centuries as al-Andalus itself evolves, Andalusians enjoyed a healthy and socializing way of eating. They combined the aboundant food in a practical and wise way, even in the poorest and most frugal cases, guided to some extent by their dieticians and men of learning, militant heirs of Greco-Roman and Oriental legacies, but also intuitively and spontaneously. These customs were favoured by a new system for working the land, fundamentally based on irrigation, and the introduction of new types of vegetables and the rational intensification of crops, which allowed them to have fresh produce all year round. They did not realize they creating what several authors would refer to as the green revolution. All of this is reflected not only in written sources but also in archaeology, especially the evidence of wildlife. Therefore the need to collate them in order to compare both worlds.
\end{abstract}

Key words. Al-Andalus; food; Mediterranean diet; agriculture; irrigation; green revolution; cooking; medicine; archaeological wildlife.

\footnotetext{
* Este trabajo se inscribe en el marco del Proyecto de I+D+i PATTERN: (P)atrimonio (A)rqueológico, Nuevas (T)ecnologías, (T) urismo, (E)ducación y (R)entabilización social: un (n)exo necesario para la ciudad histórica, concedido para el periodo 2016-2019 por la Secretaría de Estado de Investigación, Desarrollo e Innovación del Ministerio de Economía y Competitividad, dentro del Programa Estatal de Investigación, Desarrollo e Innovación Orientada a los Retos de la Sociedad, enmarcado a su vez en el Plan Estatal de Investigación Científica y Técnica y de Innovación 2013-2016, convocatoria de 2015 (Ref. HAR2015-68059-C2-1-R). Gracias a Alberto León, Rafael Blanco, Manuel Ruiz Bueno y Daniel Quesada por su ayuda con la bibliografía.
} 


\section{REFLEXIÓN DE PARTIDA}

En la actualidad conocemos mediante argumentos científicos bien probados las múltiples bondades que producen en el ser humano el consumo regular de determinados alimentos y determinada forma de comer que genéricamente, y desde no hace mucho tiempo, denominamos dieta mediterránea: una manera tradicional, mestiza, sabia y siempre abierta, por cuanto viva, de combinar los alimentos ${ }^{1}$ : aceite de oliva, vino, cereales, carnes, pescados, lácteos, miel, frutos secos, legumbres, hortalizas, etc., con fuerte carácter estacional, sabia en las mezclas, frugal ${ }^{2}$ y socializado$\mathrm{ra}^{3}$, que gusta especialmente del disfrute conjunto de la naturaleza y el aire libre, la producción autóctona y la relación con el entorno (vid. al efecto por ejemplo Bolens, 1991; González Turmo y Mataix. 2008). También, según los casos, de algo de ejercicio después de la ingesta y, por qué no, según proclamaba Avicena, de unos minutos de siesta ( $c f r$. Huetos y Salas-Salvadó, 2005: 224). Más que un simple modo de alimentación es, pues, por encima de todo, una forma de vivir, una actitud ante la vida.

Tal premisa, que vendemos como uno de los descubrimientos médicos más importantes de las últimas décadas, capaz de influir de manera decisiva en la salud media de la población ${ }^{4}$ y en su esperanza de vida, fue ya cuando menos intuida por griegos (García González, 2010) ${ }^{5}$, romanos (Vaquerizo, 2011), bizantinos (Pons y Tur, 2005), y por supuesto musulmanes, conocedores fehacientes de las propiedades nutritivas y beneficiosas de esta forma de comer - por más que no le pusieran nombre ni fueran del todo conscientes de las implicaciones que hoy conocemos-, que potenciaron y promovieron, por lo que en realidad hoy no estamos sino volviendo sobre lo que otros ya, antes que nosotros, intuyeron. Veamos a continuación

1. Básicamente, del entorno mediterráneo, si bien a día de hoy se ha enriquecido con préstamos importantes de otras zonas del mundo, en particular América (pimientos, tomates, patatas, etc.).

2. La frugalidad fue recomendada por médicos, tratadistas y escritores de todo tipo en al-Andalus (Ferhat, 1997; Martínez Enamorado, 2009: 86). Algunos autores llegaron incluso a achacar a ella la longevidad de los andalusíes ( $C f r$. Arié, 1974-1975: 308).

3. Potenciada -incluso en nuestros días- por el hecho de servir la comida en fuentes colectivas, de donde según las zonas, la época y las culturas se toma incluso directamente, sin cubiertos.

4. Que para el mundo árabe clásico es la ciencia de la medida, del equilibrio inestable entre la naturaleza del individuo, el entorno y los alimentos consumidos (García Sánchez 2005, 64).

5. Quizás por esta razón existió una amplísima literatura sobre la alimentación y su directa relación con la salud en el mundo griego de la que apenas nos han llegado testimonios. de forma breve cómo contribuyeron a todo ello los andalusíes ${ }^{6}$.

\section{EL HIBRIDISMO DE AL-ANDALUS}

Al-Andalus, como entidad política, cultural, incluso poblacional, no permanece inmutable ni en el tiempo ni en el espacio. Conviene tenerlo en cuenta de entrada para evitar caer en afirmaciones de carácter genérico que habrán de ser matizadas siempre en función de la época, el lugar y las tradiciones. Los contactos culturales entre los herederos directos de romanos y visigodos por un lado (mozárabes), musulmanes venidos de fuera (árabes o beréberes), hispanos convertidos al Islam (muladíes) y las comunidades judías que llevaban en el territorio desde muchos siglos atrás ${ }^{7}$, fueron continuos, intensos y marcados por una relativa tolerancia. Esto, sumado al desarrollo de nuevos modos agrícolas (vid. infra), a la llegada de numerosos influjos de otros lugares del Occidente mediterráneo, y a la evolución lógica de un Estado que alcanzó sus momentos de mayor esplendor entre los siglos IX y $\mathrm{X}$, asumiendo de alguna manera personalidad propia a partir de estas fechas, explica que la alimentación y la dieta en al-Andalus fueran, a pesar de la imposición mayoritaria de la religión de Mahoma y sus muchos condicionantes o restricciones al respecto ${ }^{8}$, algo híbrido, como su propia y particular idiosincrasia, compleja y de claro matiz multiétnico. Todo ello daría lugar a una nueva cocina, evocadora de muchas recetas orientales, que usa a su vez cultivos y especias importadas del otro extremo del Mediterráneo o el norte de África (magrebí), pero adaptada siempre al entorno y la casuística locales, y abierta sin reticencias a todo tipo de préstamos e influencias, incluidos por supuesto los estrictamente populares y/o vernáculos, de tradición romana o centroeuropea.

Refuerza esta afirmación el hecho de que los andalusíes basaron los principios fundamentales de su dieta y de su medicina en el mundo clásico

6. Sobre las bases arqueofaunísticas de la alimentación cotidiana en las aldeas altomedievales del Norte peninsular, vid. por ejemplo Castro Martínez, 1996; también, para otros aspectos relacionados con los hábitos dietéticos de los reinos cristianos, diferentes de los andalusíes fundamentalmente en el uso del aceite de oliva, la enorme diversificación hortofrutícola de estos últimos, y el modo de preparar y consumir los alimentos, Arié, 1974-1975, 306 ss.; García Sánchez, 1983, 183 ss.; Grau, 2009.

7. Vid. un análisis detallado de un amplio repertorio de alimentos, de sus propiedades y de su relación con la medicina y la salud en el Fi Tabdir al sihha (Régimen de la salud) que escribió en 1198 Maimónides. Lo hizo para un hijo de Saladino, sultán en varios países de Oriente, pero resulta muy ilustrativo para el tema que aquí desarrollaremos ( $c f r$. Ferre y García Sánchez, 1992).

8. No se podía consumir carne de cerdo, de ave de presa ni de carroña; tampoco sangre. 
(Hipócrates, Dioscórides, Galeno...); también, algo, en persas e hindúes (Avicena), frecuentemente a través del intermediario bizantino (Huetos y SalasSalvadó, 2005: 222 ss.; Pons y Tur, 2005). Es más, muchos de los alimentos introducidos en la península Ibérica por los musulmanes comienzan teniendo un uso fundamentalmente salutífero, al haber estudiado los médicos, caso del toledano Ibn Wafid (1008-1075) en su Libro de los Medicamentos Simples (Kitab al-adwiya al-mufrada), sus propiedades preventivas, terapéuticas o sanadoras. Más tarde, serán, entre muchos otros, figuras como la del sevillano Abu Marwan Abd al-Malik Ibn Zuhr -Avenzoar- autor de un Kitab al-Agdiya (Tratado sobre los alimentos) (Ibn Zuhr, 1992); los cordobeses Averroes, musulmán, y Maimónides, judío (Huetos y Salas-Salvadó, 2005: 225 ss.), o el nazarí de posible origen almeriense Abu Bakr Abd al-Aziz al-Uryuli9, quienes más trabajen y publiquen sobre la relación entre salud y alimentación (García Sánchez, 2005; Martínez Enamorado, 2009).

Así ocurre por ejemplo con los cítricos, destacados en uno de los dos únicos recetarios culinarios conocidos en al-Andalus, el Tratado anónimo de cocina andalusí, del siglo XIII, por sus usos medicinales para jarabes y mermeladas. Eso, por no hablar de los tratados agronómicos, que aconsejaban a los agricultores sobre cómo cuidar los campos y favorecer las cosechas, aprovechar al máximo los recursos naturales y conservar mejor determinados alimentos o producir derivados de los mismos como quesos o pan $\left(j u b z^{10}\right)$, y a la población cómo comer para que su salud se viera favorecida, conforme a «un concepto global de dietética en el que salud y ecología van estrechamente unidas», casi en forma de farmacopea (García Sánchez, 2011a: 71 y 73).

A todos estos aspectos es posible, pues, llegar inicialmente, en mayor o menor medida -en realidad bastante limitada siempre, dado su escaso número y el hecho de que no son muy explícitas-, a través de las fuentes escritas de la época (obras de médicos, botánicos, agrónomos ${ }^{11}$, juristas, escritores, viajeros, cocineros y dietistas, de utilidad desigual aun cuando

9. Siempre con base en obras y autores clásicos, musulmanes y hebreos anteriores a él, entre los que no faltan Dioscórides o Averroes, Al Uryuli redactó entre 1414 y 1424 un nuevo tratado sobre los alimentos en el que glosa las cualidades de los mismos (cereales y leguminosas, carnes, encurtidos, especias, pescado y anguilas, leche y lácteos, frutas frescas y secas, etc.) con afanes casi bromatológicos (Díaz García, 1979-1989; 1983).

10. Este era el término genérico en árabe para denominar el pan, con independencia del grano y el método utilizados para su elaboración (García Sánchez, 1983: 141).

11. Algunos autores hablan de una verdadera «escuela agronómica andalusí» que habría conocido su edad de oro entre los siglos XI y XII (García Sánchez, 1983: 184). complementaria) ${ }^{12}$, pero también a través de los numerosos tratados de hisba, redactados entre los siglos IX y XIV para el buen gobierno de la ciudad islámica (García Sánchez, 1983: 186; 1995: 49; 1996: especialmente $221 \mathrm{ss}^{13}$ ). Servían para recordar que era preciso hacer el bien y fijar el papel del almotacén (muhtasib) en la vigilancia de las costumbres y del orden moral y cotidiano en la ciudad y en el zoco, donde se vendían la mayor parte de los productos alimenticios y multitud de comidas preparadas, a las que siempre han sido muy aficionados los musulmanes. Son, en este sentido, muchos los autores recientes que se han acercado al tema de la alimentación andalusí en las últimas décadas ${ }^{14}$, por lo que remito a ellos para una revisión en profundidad del tema, limitándome por mi parte a llamar la atención sobre la necesidad ineludible de trabajar en el futuro de manera interdisciplinar; metodología que, bien planteada, puede contribuir a confirmar, matizar o corregir hipótesis.

\section{AGRICULTURA Y GANADERÍA}

Desde muy antiguo, las fuentes básicas de nutrición en las tierras que bordean el Mediterráneo fueron el cereal, el vino y el aceite, a los que se sumaba en muchas zonas la higuera. Un paisaje, por tanto, con el que se identificaban absolutamente los árabes que en el siglo VIII invaden la Península Ibérica, y cuantas oleadas de gentes foráneas (procedentes en esencia del norte de África), irán llegando a estas tierras hasta su expulsión definitiva en el siglo XV (García Sánchez, 1997a); gentes que se preocuparán por conocer el legado de sus antepasados griegos y romanos en todos los órdenes de la ciencia y de la vida, e investigarán sobre la mejora del cultivo y de la producción, legándonos numerosas obras de las que es posible colegir a día de hoy su pensamiento, sus técnicas y sus considerables avances (Viguera, 2007).

12. A ellas hay que sumar los famosos Calendarios, muy particularmente el conocido como Calendario de Córdoba (Dozy, 1873; Pellat, 1961), que entre otros aspectos contienen información sobre la adecuación de los cultivos, las tareas agrícolas, las especies botánicas (López López, 1994) e incluso la dieta según las diversas épocas del año.

13. Esta misma autora incluye a partir de la página 233 del último de sus trabajos citados una cumplida e interesantísima relación de los alimentos y los platos más populares que se vendían en los zocos, así como de los oficios y gremios documentados en ellos en relación con la alimentación, a la que añade las respectivas transcripciones al árabe de los nombres de unos y otros. Al respecto, vid. además García Sánchez (1990), verdadero vademécum sobre la cocina andalusí de época tardoislámica.

14. Destacan entre ellos, por sólo poner algunos ejemplos, E. García Sánchez, M. Marín, o M. Oubahli, que han trabajado fundamentalmente sobre las fuentes escritas, y cuentan, en particular las dos primeras, con multitud de publicaciones al respecto (vid. relación bibliográfica final). 
Según todos los datos disponibles, la agricultura hispana conoció en los siglos finales del Imperio Romano y durante el dominio visigodo una fuerte regresión. Pobre y escasamente diversificada, concedía al pan y al vino un papel esencial en la dieta (García Sánchez, 1983: 183). Esto no significa que desapareciera por ejemplo el tan importante para la alimentación de las clases populares cultivo del olivo ni la producción de aceite (vid. infra), según se desprende, entre otras fuentes, de las Etimologías de San Agustín, que distingue varios tipos, entre los cuales destaca el hispano, obtenido al parecer de aceitunas blancas (Garrido et al., 2007: 262). Los árabes encontraron en el Occidente mediterráneo un paisaje y unos usos agrícolas similares a la que ellos habían practicado siempre, con tan sólo una, pero gran diferencia, vital, y de enorme trascendencia: la mayor abundancia de agua, la mejor calidad de las tierras y, en consecuencia, una feracidad desconocida que reforzaron con la introducción de numerosos cultivos de origen asiático y africano hasta entonces desconocidos por estos lares (arroz, naranja, plátano, sandía, limón, alcachofa, alubia ${ }^{15}$, berenjena, espinaca, cidra, caña de azúcar ${ }^{16} \ldots$...) (Watson, 1998; Trillo, 2007), o la generalización, selección y mejora de otros ya conocidos pero poco explotados -como por ejemplo el peral, cultivado y silvestre-, que hoy siguen siendo absolutamente básicos en nuestra dieta. Muchas de estas nuevas especies fueron aclimatadas en los grandes jardines y huertas de los palacios y almunias de monarcas y cortesanos, que actuaron con frecuencia como jardines botánicos. Fue el caso de la Arruzafa, construida en la falda de la sierra de Córdoba por el primer emir omeya, Abd al-Rhaman I, a finales del siglo VIII, iniciando con ello un modelo que sería después imitado a todo lo largo y ancho de al-Andalus (García Sánchez, 2011a: 68).

Tales prácticas trajeron también consigo la introducción de nuevos métodos de cultivo; la imposición del abonado de los campos -sometidos en muchos casos a re-parcelaciones casi minifundistas que imponen un paisaje de huertas, bancales y cultivos intensivos-; la supresión del barbecho, con lo que esto supuso para la multiplicación de las cosechas, o una nueva, sofisticada y muy bien regulada gestión del agua, materializada en el diseño de sistemas muy desarrollados e

15. De un tipo obviamente distinto del americano (Díaz García, 1982-83: 13).

16. Aun cuando no existe unanimidad a la hora de valorar su incidencia en al-Andalus (García Sánchez, 1983: 187; 1989; 2002: 174 ss.; Díaz García y Malpica, 1988; Malpica, 1995; Barceló y Labarta, 1998; Martínez Enamorado, 2009: 76), no parece haber problema en aceptar un foco de producción en el entorno de Motril y Salobreña. En cualquier caso, el azúcar fue considerado siempre un producto de lujo, de consumo minoritario y limitado a las mesas más pudientes. ingeniosos de irrigación ${ }^{17}$, y en la diversificación de cultivos. Todos estos aspectos, que según las últimas investigaciones se vieron también acompañados de una intensificación de la actividad ganadera (GarcíaGarcía y Moreno-García s/f: 10), terminaron por influir poderosamente en la transformación del paisaje físico y humano del sur peninsular, así como en la mejora de la alimentación, bastante más diversificada, abundante y saludable que la del resto de pueblos peninsulares (incluso europeos) por una simple cuestión de sabiduría, pragmática, capacidad técnica y equilibrio ${ }^{18}$.

Estas novedades convirtieron el nuevo territorio conquistado -porque fue precisamente la zona peninsular más propicia para su cultivo la que quedó bajo el dominio de al-Andalus- en un auténtico vergel. Por más que el término pueda, a día de hoy, ser en mayor o menor medida cuestionado, algunos investigadores han llegado incluso a hablar de revolución agrícola, o revolución verde andalusí (Watson, 1998), reforzada en cualquier caso por numerosos tratados de agronomía que ven la luz sobre todo entre los siglos $\mathrm{X}$ e inicios del XIII (el último sería escrito en Almería por Ibn Luyûn en el siglo XIV). Por supuesto, esto no quiere decir que en un sistema agrario complejo como el andalusí desapareciera la agricultura extensiva y de secano, centrada básicamente en cereales y gramíneas, alternados como mandan los cánones con el lino y las leguminosas para oxigenar las tierras (así por ejemplo en tierras de Granada; Trillo, 1999: 134); antes al contrario, en la convivencia y la armonía entre ambas está una de las claves del éxito del nuevo sistema de explotación agrícola andalusí, adaptado en cada caso a la mayor potencialidad de aquéllas según las zonas, el clima y la abundancia de agua (Bolen, 1981; García Sánchez, 2011a: 64 ss.).

Por lo que se refiere a la ganadería, las fuentes no son tan explícitas, y quizás por eso ha llamado menos la atención de la comunidad investigadora, más atraída

17. «... esfuerzo mudo de generaciones de campesinos cuyo ingenio y laboriosidad transformaron desiertos en vergeles, generando la riqueza material que sustentó el extraordinario esplendor de la cultura andalusì (Huetos y SalasSalvadó, 2005: 228). Estos sistemas de riego se extendieron también a los viñedos (karm; pl. kurum) cuando se trataba de uva de mesa, y ocasionalmente al olivar, cultivado por lo general en explotaciones pequeñas y régimen de autoproducción. Los viñedos fueron muy característicos del entorno de Granada y su Vega en época nazarí. De hecho, el término árabe que los designaba acabaría derivando en el de «carmen», que da nombre hoy a las residencias de recreo con vocación campestre y omnipresencia de los emparrados, tan típicas del Albaicín o las riberas del Darro (García Sánchez, 2011a: 71).

18. Entre la numerosísima bibliografía reciente sobre el tema vid., por ejemplo, Bolens, 1981; Guichard, 1982; Watson, 1983; Glick, 1992a; 1992b; Glick y Kirchner, 2000; Barceló, 1989; 1995; 2004; Barceló et al., 1998; Riera, 2005; Sitjes, 2006; Guinot, 2007; Grau, 2009; Retamero, 2009; García Sánchez, 2011a: 64 ss. y 76. 
por el boom de la agricultura y las innovaciones de todo tipo introducidas en ella por los andalusíes, que por la economía animal del mismo periodo. Tal circunstancia se ha traducido en un vacío historiográfico importante $^{19}$ que, curiosamente, empieza a ser llenado en buena medida desde la Zooarqueología ${ }^{20}$ ( $v i d$. infra). A diferencia de lo que opinan algunos autores (Watson, 2007), ganadería y agricultura no fueron nunca excluyentes ni tuvieron por qué ir disociadas, dados:

- la particular orografía peninsular, que alterna de forma natural zonas especialmente proclives al regadío con otras de secano más aptas para el ganado;

- el destino eventual de ciertos sectores irrigados, por lo general, de pequeño tamaño, para la producción de forrajes o de leguminosas con los que alimentar a aquél cuando faltan los pastos;

- y las posibilidades que una cabaña ganadera cuando menos de tipo doméstico y autosuficiente, de alcance diferente según se trate de áreas urbanas, suburbanas o rurales, ofrece para limpiar las tierras de barbechos o malas hierbas y también para estercolarlas, con su consiguiente enriquecimiento de nutrientes.

A partir de ahí, la existencia o no de grandes rebaños, que necesitarían de prados amplios y fértiles en una cultura que primó la producción agrícola, habrá de ser confirmada (o no) por la investigación futura, que cuenta ya con algunos trabajos relativos al pastoreo, el papel de los abrevaderos en las rutas ganaderas, la importancia de la sal en la alimentación de los animales, o la incidencia del mismo en determinadas etapas y áreas geográficas (vid. por ejemplo al respecto Cara y Rodríguez, 1989; Malpica, 2011; 2012: 226 ss.; Malpica et al., 2011; Trillo, 2011). Sin embargo, a día de hoy son los análisis arqueofaunísticos los mejores indicadores de la importancia que el consumo de carne desempeñó en la alimentación andalusí, de las especies animales más frecuentes y demandadas (que por otra parte se aprovecharían con carácter integral, en la vida, como en la muerte), de los sistemas de producción ganadera según zonas y momentos, y también de las implicaciones sociales, económicas, religiosas, rituales o simplemente culturales de todo ello (García

19. «La consecuencia más evidente de todo ello ha sido la construcción de una visión del mundo rural andalusí en la que la ganadería se mantiene disgregada no sólo de la vida agrícola, sino también de la vida social de las comunidades campesinas andalusies» (García-García y Moreno-García, s/f: 2).

20. Destacan en este sentido investigadores que a su condición de historiadores unen la de zooarqueólogos, caso de M. García-García, de la Universidad de Granada/University of Sheffield.
García y García Moreno, s/f; Torres, 1988; García García, 2011; 2012; 201421).

Veamos a continuación qué dice sobre varios de estos aspectos la arqueología.

\section{LA ALIMENTACIÓN EN AL ANDALUS. LA VOZ DE LA ARQUEOLOGÍA}

A la falta de estudios de conjunto sobre el tema que aquí nos ocupa se suma la relativa escasez de excavaciones arqueológicas en las que se hayan realizado análisis científicos de paleoambiente (aequeobotánica, palinología, carpología, antracología, paleofauna, etc. $)^{22}$, o de necrópolis de las que se hayan extraído deducciones sobre paleodieta, enfermedades o carencias alimenticias que permitan contrastar la información transmitida por las fuentes escritas con la realidad arqueológica ${ }^{23}$. Con todo, en los últimos años comienzan a menudear algo más, de la mano de un incremento del rigor metodológico en las intervenciones y de un importante reforzamiento de dichas tendencias historiográficas, empeñadas en demostrar día a día su enorme potencialidad.

Como es fácil entender, no tendría sentido intentar aquí una recopilación de los trabajos publicados sobre el tema de pretensiones exhaustivas -nunca completadas, por razones obvias-, en el marco cambiante -en el tiempo y en el espacio, como más arriba indicabade al-Andalus, entre otras razones porque no es ése el objetivo de mi trabajo, pero sí quiero traer a colación algunos de ellos por lo que tienen de ilustrativos y por cuanto ratifican en buena medida las posibilidades de esta metodología.

\section{NECRÓPOLIS}

Desde el punto de vista funerario contamos ya con algunos análisis de caso, como el aplicado a los restos humanos de la necrópolis de Tauste (Zaragoza) (Guede et al., 2015), en la que ha sido detectada una dieta basada principalmente en la ingesta de verduras, frutas y cereales, con un cierto matiz diferencial entre los hombres y las mujeres, que consumirían menos proteínas y plantas del tipo C4, circunstancia achacada por los investigadores a cuestiones relacionadas con el trabajo que realizaban y las posibles menores necesidades

21. Otros muchos títulos infra.

22. El estudio y la difusión de las plantas en al-Andalus ha sido objeto recientemente del proyecto de investigación HAR2010-21932-CO2 Selección y gestión de plantas en alAndalus. Prácticas campesinas y estados, coordinado por Helena Kirchner, de la Universidad Autónoma de Barcelona (vid. infra).

23. «La posibilidad de contrastar tres registros diversos como el textual, la reconstrucción del espacio agrario y el carpológico es inédita en los estudios sobre historia y arqueología agraria de al-Andalus» (Kirchner et al., 2014: 34). 
nutricionales de éste, o quizá sólo a una cuestión de género. La misma tendencia se ha observado en la necrópolis islámica de Écija (Pomeroy y Zakrzewski, 2009), y marcadores de trabajos distintos en hombres y en mujeres son evidentes en la de Marroquíes Bajos (Jaén) (Aran Herrera, 2012).

\section{AgRicUltura Y ESPECIES CULTIVADAS}

En lo referido a la agricultura y los sistemas de cultivo, en al-Andalus destaca por méritos propios el trabajo recientemente publicado sobre Madîna Turtûša (actual Tortosa) y su huerta (unas $85 \mathrm{Ha}$ ) en el momento misma de ser reconquistada (1148). Además de lo que representa de puesta al día ${ }^{24}$, incluye un interesante estudio desde la perspectiva de la nueva «Arqueología Hidráulica» sobre sistemas de regadío y aprovechamiento del agua, parcelaciones y dedicación de las tierras, cultivos constatados (prevalecieron los cereales, los higos, las uvas y los olivos) y muestras carpológicas, fundamentalmente de los siglos X y XI.

Entre las especies identificadas se relacionan el trigo desnudo, tres variedades de cebada, el mijo menor, el lino, la higuera, el olivo, la vid, el hinojo, la dulcamara $^{25}$, la manzanilla hedionda, la avena silvestre, el cenizo blanco, el raigrás, la malva, el alpiste, la centinodia, la rabaniza, la acederilla, la verbena común, la veza hirsuta y el bayunco. Con excepción del hinojo y la dulcamara, cuyo cultivo pudo ser intencionado, o por lo menos tolerado, la relación indicada a partir de la manzanilla hedionda entra directamente en la categoría de malas hierbas, por regla general asociadas a la cebada vestida y cultivos de primavera, destinados al pastoreo después de la siega, con lo que eso implica de relación entre agricultura y ganadería (vid. supra). No se han encontrado restos de frutales, quizás porque eran cultivados en otras zonas del territorio. De hecho, tampoco son citados por los beneficiarios de los repartimientos tras la conquista, que «se apropiaron de estructuras agrarias campesinas y las convirtieron en fuentes de renta» (Kirchner et al., 2014: Cuadro 2, y en particular 28 ss.).

24. Se recogen por ejemplo los resultados obtenidos en Madina Larîda, Madîna Balagî y Madîna Yabîsa: «En las dos primeras, además de los cereales (cebada, trigo desnudo, avena), también se han encontrado lentejas y numerosos restos de frutas: semillas de uva, de higos, almendras, huesos de olivas, nueces, peras, manzanas, ciruelas, pepino o melón» (Kirchner et al., 2014: 16)

25. Planta silvestre que puede ser cultivada de manera controlada en los márgenes de las huertas. Tiene propiedades antisépticas, aunque en dosis elevadas resulta tóxica y puede llegar a producir la muerte.

\section{ESPECIES ANIMALES}

Desde el punto de vista estricto de la arqueofauna, contamos ya con numerosos trabajos basados en intervenciones arqueológicas en al Andalus; alguno de ellos referido a la propia capital, Qurtuba. Destaca en primer lugar, por cronología e importancia, el arrabal emiral de Saqundah (Casal et al., 2010; Martínez Sánchez, 2012), de viejos ecos hispanorromanos. Su nombre deriva del miliario alusivo a la segunda milla de la via Augusta, y según las fuentes muchos de sus pobladores eran muladíes. Fue un barrio populoso, ubicado al otro lado del río (se conoció de hecho como arrabal meridional, al rabad al-yanubi), cuyos habitantes, fundamentalmente comerciantes, artesanos y gente de condición humilde, se levantaron en 818 contra los abusos fiscales del emir al Hakam I, desapareciendo casi en el envite: el enclave por arrasamiento, y sus vecinos por deportación. Ya en el siglo XIII, bajo el poder de los almohades, Ibn Sa'id, en su Al-Mugrib fì hulā al-Magrib, dice de él: «Antiguamente fue ciudad, pero después fue arruinada y hoy es una aldea que domina Córdoba y es vecina de ella» (cfr. García Gómez, 1976: 48, con muchas más referencias textuales al viejo arrabal saqundí).

De Saqundah se habían conservado, pues, los ecos histórico-legendarios, pero nada más, hasta que con motivo de la remodelación urbanística de la zona, entre 2001 y 2002, los arqueólogos del Convenio GMUUCO (León Muñoz y Vaquerizo, 2012), bajo la dirección de $\mathrm{M}^{\mathrm{a}}$ Teresa Casal (Casal 2008, con bibliografía anterior), pusieron al descubierto los cimientos de un amplísimo sector del arrabal $\left(16.000 \mathrm{~m}^{2}\right)$, conformado por estructuras domésticas, comerciales e industriales organizadas en torno a calles de hasta seis metros de anchura, con técnicas constructivas, tipologías y servicios muy diferentes a los que más tarde nutrirían los grandes arrabales califales. Con motivo de dichas excavaciones pudieron ser estudiados allí hace unos años los restos faunísticos de varias fosas basurero de ámbito doméstico y formación rápida-quizás por obedecer a restos de fiestas o celebraciones concretas-, asociados en su mayor parte a la primera fase constructiva del arrabal (Casal et al., 2010), cuya vida, en cualquier caso, no duró mucho más de 70 años. Los depósitos en cuestión estaban ubicados en patios domésticos, y han testimoniado un consumo preferencial de ovicápridos, sacrificados como es habitual mediante degüello, preferentemente añales o carneros ${ }^{26}$, además de alguna

26. Se confirman así las recomendaciones recogidas en los tratados sobre los alimentos de la época: «La mejor carne de ganado es la de cordero añal, de un año cumplido. Es la de sabor más agradable, y al mismo tiempo la que contiene un mayor alimento (...). A la carne de cordero añal le sigue en calidad la carne de carnero que ha echado sus primeros dientes, ya que es menos jugosa, y de complexión más proporcionada que la carne de borrego y oveja (...)» (A1Uryuli, Al-Kalam 'Alà l-Agdiya, III, 32-33; cfr. Díaz García, 1983: 6). 
oveja vieja, perdida sin duda su función reproductora. Les siguen los bóvidos ${ }^{27}$, y en tercer lugar las aves - no especifico porcentajes, porque éstos varían de manera considerable según se refieran a la proporcionalidad de las diferentes especies identificadas o al peso de los restos conservados-, sobre todo gallinas domésticas y gansos, que producirían carne y por supuesto huevos, de gran importancia para la ingesta de proteínas, además de algunas palomas, codornices y perdices ${ }^{28}$.

También se detectó la presencia, aun cuando en valores muy poco significativos, de pescado y moluscos, un perro y un gato, algún équido (seguramente asno) -los cuatro últimos sin signos de descuartizamiento ni de haber servido para usos alimentarios-, tal vez un cérvido, y cierta representación de conejo. En época emiral los restos de conejo deben serlo muy probablemente de la modalidad silvestre o de liebre, por cuanto la cría doméstica de este animal no parece probada en Europa hasta el siglo XII. Sin embargo, esto no implica procedencia rural, puesto que debió haberlos (todavía los hay) en las frondas que flanquean ambas márgenes del Guadalquivir a su paso por la ciudad. V. Martínez Enamorado (2009: 90) defiende que la carne de conejo no se vendía en los zocos; afirmación que contradice con rotundidad E. García Sánchez (1986: 242), para quien su venta era, en cambio, frecuente y masiva. De hecho, conejos y liebres tenían que venderse desollados porque en caso contrario la carne se estropeaba con mucha rapidez. No es difícil encontrar huellas de tales prácticas en los análisis de arqueofauna practicados en algunos yacimientos (Moreno-García y Davis 2001: 243).

Esta ausencia de carne de caza en la dieta documentada en Saqundah incide en el carácter plenamente urbano del gran arrabal emiral (Casal et al., 2010: 171 y 177); lo que no evita que, como antes señalaba, pudiera contar con una cierta cabaña ganadera alimentada en los campos cercanos. Llama también

27. En una de las fosas (la más singular de ellas, por sus características diferenciales, que hacen dudar a los autores a la hora de atribuirla a una u otra categoría) fue recuperado el esqueleto completo de una vaca de seis o siete años de edad, seguramente estabulada y lechera, que pudo morir a consecuencia de una fractura en la tibia derecha. La presencia de cierto número de ovicápridos no sacrificados a pesar de haber sufrido fracturas en alguna de sus patas parece abogar por el carácter doméstico y estabular de los mismos, quizás con el mismo fin (Casal et al., 2010: 165 y 175, Fig. 10). Esto confirmaría la presencia de una cabaña ganadera quizá mínima, pero de vocación autosuficiente, incluso en medio urbano.

28. «Entre las mejores carnes de ave está la de perdiz, que es como una gallina silvestre, y es una de las cosas que sirven contra el estreñimiento, y dice Averroes que si se cuece su efecto es mayor. A la carne de perdiz le sigue la de perdiz blanca (tayhuŷ) y la de paloma torcaz (yamam), que son muy nutritivas, fortalecen la mente y agudizan el entendimiento» (Al-Uryuli, Al-Kalam 'Alà l-Agdiya, IV, 56; cfr. Díaz García, 1983: 10) la atención la clamorosa ausencia del cerdo; algo que no ocurre en la fase emiral del arrabal de Cercadi$1 \mathrm{la}^{29}$, objeto reciente de un estudio arqueofaunístico (García García 2016) que compara sus resultados, muy similares en todo lo demás a los de Saqundah, con los de Madinat Ilbirah. Dicha obra es significativa de la enorme potencialidad que ofrecen este tipo de estudios a la hora de comparar dinámicas poblacionales, culturales y socioeconómicas, en este caso urbanas, en el marco de al-Andalus, y sus respectivos procesos de islamización. Finalmente, tanto en el arrabal meridional de Qurtuba como en otros muchos yacimientos son bastante frecuentes las ratas (vid. por ejemplo, infra, El Maraute, en Motril; Riquelme, 1991, 108-109).

Los basureros de Saqundah llevaban asociado abundante material cerámico, en el que dominan ollas, jarros, jarras y tapaderas, con una representación mucho menor de botellas, cuencos, tinajas, orzas, lebrillos y candiles ${ }^{30}$. Entre los jarros destaca el tipo 2.1.2.2.c, de grandes dimensiones, destinado al almacenamiento del líquido elemento, hecho muy significativo si tenemos en cuenta la escasez de pozos de agua en el arrabal, ubicados además en espacios comunitarios. A este respecto es importante recordar que en Córdoba tradicionalmente no se ha bebido del río, por lo que es de suponer la existencia de puntos de aguada públicos, y también la actuación de aguadores.

Valores muy similares a los de Saqundah habían sido obtenidos algunos años antes a partir del análisis de los fragmentos óseos (identificados por su tafonomía como restos de comida) recuperados en Madinat al-Zahra, Córdoba: además de la habitual ausencia de suidos, destaca el porcentaje de ovicápridos y pequeños rumiantes en la Casa de Yafar (81\%), frente al de las casas de servicio (64\%); la escasísima representación de bóvidos en ambos sectores (pero más aún en el primero), sólo relativamente achacable a un bajo

29. Sobre el complicado papel de éstos en depósitos arqueofaunísticos andalusíes, y su posible atribución a poblaciones no islámicas, vid. el estudio incluido en Davis et al., 2008. No obstante, a juicio de algunos investigadores cabe dentro de lo posible que determinadas comunidades campesinas de base musulmana pudieran haber comido cerdo sin demasiados problemas de conciencia, dada su facilidad de cría y su extraordinario aprovechamiento (Martínez Enamorado, 2009: 74 ss.). No faltan incluso referencias en las fuentes escritas de la época que aluden a la práctica de «matar puercos» y califican al cerdo como la mejor de las carnes para el consumo humano (García Sánchez, 1986: 240 y 246 ss.).

30. Sobre la tipología cerámica documentada en Saqundah y su directa relación con la cocina, vid. además López Guerrero 2010. Son muy importantes al efecto de relacionar las formas cerámicas documentadas en los yacimientos andalusíes con sus respectivas funcionalidades los trabajos de G. Rosselló (vid. por ejemplo 2002, con bibliografía anterior). También, alguno de M. Marín (1996) y, más recientemente, Hita et al. (2009), por sólo poner algunos ejemplos. 
consumo de esta especie ${ }^{31}$, quizá reservada para otros usos; la posible presencia entre las aves, con un porcentaje en su conjunto del $14 \%$ y el $24 \%$, respectivamente $^{32}$, y el típico predominio de las gallináceas ${ }^{33}$, de otras menos frecuentes como avutardas y zancudas; y, por fin, algún ejemplar de cérvido y lepórido (conejo o liebre) (Agüera et al., 2005).

Otro caso cercano, y muy significativo, es Priego de Córdoba (la antigua Madinat Baguh) donde, a fin de recrear tanto la economía animal como las actitudes sociales relacionadas con la ganadería, el consumo y el tratamiento de las carnes domésticas y silvestres, han sido analizadas un millar de muestras óseas recuperadas en diez depósitos de distinta morfología y origen fundamentalmente culinario, comprendidos entre las épocas emiral y nazarí (ss. IX-XV). De entrada, quizá lo más destacado desde el punto de vista de la dieta es el contraste entre la ausencia de cerdo y jabalí en los contextos de los siglos IX a XIII, y su abundancia en los posteriores a la segunda mitad del siglo XIII. Priego no sería conquistado definitivamente hasta 1341 , pero ya antes la población, que permanece durante mucho tiempo fronteriza con el reino nazarí, había cambiado varias veces de manos y esto explicaría quizás la contaminación del modo original de comer por parte de los musulmanes. Hasta ese momento prevaleció absolutamente el consumo de ovicápridos, bóvidos y aves, en valores muy similares a los detectados en Saqundah, aun cuando por regla general se documentaron individuos sacrificados en edades más tempranas, sobre todo en el caso de los primeros, lo que a juicio de los autores del estudio parece confirmar una ganadería más orientada a la producción de carne que de leche o de lana, si bien yo añadiría un componente de selección según sexo, que apartaría los machos para el sacrificio y reservaría las hembras para la cría y la obtención de leche y lana, más o menos como se sigue haciendo hoy en cualquier explotación ganadera. Los restos de especies silvestres no son representativos, destacando sólo los valores recuperados en el interior del castillo; un incremento de la muestra que ha sido relacionado con prácticas «deportivas» o de clase, y quizás también con derechos exclusivos de caza, propios del ejército o de las clases sociales más elevadas (Martínez Sánchez, 2012: 308; Martínez Sánchez y Carmona, 2013).

En la órbita de Priego, que fue cabeza de cora, hay que valorar la alquería ocupada entre los siglos IX y X

31. «Esta baja proporción nos hace pensar que si realmente estos hallazgos procedían de platos consumidos, lo usual es que la carne de esta especie se preparara desprovista de huesos (filetes) y tan sólo algunos guisos de cola (rabo de toro), o de los miembros (osobuco) se harian acompañar de huesos» (Agüera et al., 2005: 47).

32. Algo superior al habitual.

33. Más pequeñas que las actuales, en la línea de la «gallina moruna» que se conserva todavía en zonas rurales de Andalucía. en el Cerro de la Cruz (Almedinilla, Córdoba), que algunos autores han querido identificar con la Wasqa citada por Ibn Hayyan y Al-Udri (Carmona Ávila, 2010: 118). De ser así, su población habría tenido un componente básicamente árabe. Pues bien, también allí han sido estudiados varios depósitos excavados entre 2006 y 2008 que, si bien presentan una baja representatividad en cuanto a número de restos, evidencian de nuevo valores muy similares a los ya comentados, con cierta tendencia a la paridad entre caprinos y bovinos, y presencia de alguna cabra salvaje, un asno, conejo, diversos tipos de aves y perro doméstico. Como suele ser habitual en poblaciones de religión estrictamente musulmana, no ha sido detectado el cerdo (Martínez Sánchez, 2010: 142 ss.; 2012, 307).

Un patrón muy similar al de Saqundah -y por extensión al de Madinat Baguh y su cora- se observa en el conjunto arqueofaunístico de finales del siglo IX procedente de dos basureros excavados en el asentamiento islámico de Cerro Miguelico (Torredelcampo, Jaén) (Paz Martínez y Tussell, 2000). Los restos, en muy buen estado de conservación, fueron recuperados mediante excavación sistemática y corresponden a dos fases distintas, quizás no extrapolables a la totalidad del yacimiento. Como es habitual en los patrones alimenticios de esta época, priman sin matices los restos de ovicápridos, sacrificados muchos de ellos con menos de diez meses, y en su mayor parte en edad inferior a los tres años, buscando el máximo aprovechamiento cárnico. Les siguen las aves, básicamente gallo/gallina, con mayor representación de los individuos jóvenes (menos de seis meses), alguna gallina ponedora y un par de perdices. Esto contradice la idea de que el consumo de gallinas y gallos se postergara sistemáticamente en al-Andalus hasta que los animales hubieran perdido utilidad; una cuestión de simple sentido común cuya casuística sería enorme y parece difícil de establecer. También aparece documentada, en tercer lugar, la paloma, aunque no se ha podido determinar si doméstica o silvestre (Hernández Carrasquilla, 1993) $)^{34}$.

A los galliformes les siguen en Cerro Miguelico los lagomorfos (conejo/liebre ${ }^{35}$ ), y una cierta presencia de bóvidos (quizá buey, de año o año y medio), équidos (un caballo/asno de más de quince meses), cérvidos (como mínimo un individuo, que junto a la perdiz confirman el consumo de carne de caza) y suido: una escápula y dos incisivos en la Fosa I, de explicación controvertida. Huellas de despiece han sido observadas

34. En Castelinho (Almodóvar, Portugal), predomina en los registros faunísticos la carne de caza (Cardoso, 1993: 106). Esto da idea de la diferente dinámica que testimonian los yacimientos andalusíes en lo que se refiere al papel de las especies silvestres en la dieta diaria de las poblaciones urbanas y campesinas (o al menos a la presencia de la misma en los yacimientos estudiados) y su posible adaptación al entorno.

35. Es posible que no todos consumidos. 
de manera especial en los ovicápridos, cuyas canales fueron seccionadas longitudinalmente después del degüello -los cortes de éste dejaron algunas huellas en los hioides del cuello-, y sus cuartos separados y/o troceados buscando preferentemente las epífisis y diáfisis, proximales o distales. En algún caso podrían haberse sacrificado animales enfermos; se ha detectado de hecho alguno con periodontitis, que se intentó combatir mediante corte y sangrado de las encías, a tenor de las marcas dejadas en los huesos de la mandíbula.

Otro ejemplo de interés en la zona, dado a conocer hace muy pocos años, es el de Madinat Ilbirah, centro rector de la Vega de Granada entre los siglos IX y XI (García García, 2014; 2016). A partir de un registro arqueofaunístico de unos 1.400 fragmentos óseos recuperados en excavaciones arqueológicas practicadas en diversos sectores del yacimiento entre 2001 y 2009, se ha podido confirmar, con sólo pequeños matices diferenciales entre unas zonas y otras, la habitual supremacía de ovicápridos (en particular de la oveja, que casi duplica a la cabra), con casi el 60\% del total de la muestra y preferencia por los individuos jóvenes o adultos hasta los tres años, seguidos de los galliformes (algo más del 18\%), mayoritariamente pollos, lo que indica una cría destinada al consumo, los lagomorfos (alrededor del 15\%) y los bóvidos (4\%). No faltan algunos restos de paloma, ciervo, équido y otras especies, casi siempre domésticas y no por fuerza relacionados con la alimentación. También se han documentado congrio, atún, besugo y caballa, testimonio de un contacto directo y regular con la costa, si bien resulta difícil fijar el papel que este tipo de productos del mar desempeñaron en la dieta cotidiana de Madinat Ilbirah. Todo ello se inscribió en un modelo económico de gestión ganadera que ha sido calificado de autosuficiente y que incorporó el máximo aprovechamiento de los recursos animales y sus derivados (García García, 2012).

A término municipal de Motril, siempre en el marco de la actual provincia granadina, se adscribe el yacimiento califal (siglos X-XI) de El Moraute (Riquelme, 1991), donde ha sido constatado el ya consabido predominio de ovicápridos (casi el 70\%, casi siempre jóvenes), seguidos a bastante distancia y en este orden de galliformes, bóvidos (también de corta edad; criados, pues, para el sacrificio ${ }^{36}$ ) y lagomorfos (sólo conejo, posiblemente salvaje). Una minúscula porción de los restos estudiados fue puesta al fuego, si bien cualquier interpretación al respecto ha de ser gobernada por la cautela ${ }^{37}$.

36. Esta circunstancia no es habitual en la época; mucho menos en las zonas rurales. Los bóvidos ofrecen la posibilidad de ser dedicados al trabajo y a la producción, por lo que en el mejor de los casos se consumen animales viejos, que ya han dejado de ser útiles, o lisiados.

37. Otros estudios relativos al propio Motril y a la ciudad de Granada, con valores no muy diferentes, en Riquelme 1993 y 1995 , respectivamente.
Significativo al respecto del tema aquí analizado es, igualmente, el caso de Sevilla, objeto de numerosos trabajos en los últimos años a cargo de Eloísa y María Bernáldez (1998; 2002; 2004, entre otros). Destaca por ejemplo el análisis de los desechos paleoorgánicos documentados entre los escombros utilizados en la construcción de la catedral (Bernáldez y Bernáldez, 2002: 430), posiblemente trasladados desde los muladares de la ciudad, pero correspondientes en cualquier caso a ámbitos domésticos urbanos y como es habitual siempre parciales, en este caso además debido a numerosos factores añadidos de pérdida ${ }^{38}$. Aun así, son pista importante a la hora de reconstruir las costumbres y la dieta de quienes los generaron, por más que la frecuencia de las especies enterradas no siempre se corresponda con la de las consumidas, criadas o cultivadas. Siguiendo los patrones habituales ya comentados más arriba, los siglos XI y XII destacan por una mayor presencia de la fauna de consumo -en particular oveja y/o cabra, seguidas de vacas, pollos y conejos, quizá domesticados, una muy escasa representatividad del cerdo y cierta abundancia de perros-, en contraste con los siglos propiamente cristianos. Son valores muy similares a los documentados en el basurero islámico adosado a la muralla del Hospital de las Cinco Llagas, actual sede del Parlamento andaluz, tal vez generado por el arrabal de la Macarena, que desapareció tras la conquista cristiana. Su sorprendente identidad, incluida cierta presencia de cerdo en niveles islámicos que, como en Cercadilla, no tiene por qué corresponder a gentes de esta religión, así como bolsadas de caracoles en edad de consumo aun cuando más pequeños que los actuales, parece arrojar algún tipo de patrón en la conformación de los mismos, a pesar de situarse los dos muladares en extremos opuestos de la urbe (Bernáldez y Bernáldez, 2004).

Esta misma preponderancia de los ovicápridos (en particular de la oveja), con mayor peso de los individuos jóvenes y un aprovechamiento intensivo de los mismos, incluida la médula ${ }^{39}$, que observamos en los casos anteriores, ha sido detectada también en otros yacimientos islámicos peninsulares. Sirvan como ejemplos Murcia, donde, aparte de bóvidos y de aves, los restos analizados en un contexto culinario doméstico han evidenciado de nuevo en proporciones apreciables conejo (incluida la liebre) y también asno, si bien la presencia de éste no tiene por que ser relacionada con prácticas alimenticias (Lluró, 1991); la rábita califal

38. «Al interpretar el contenido paleoorgánico de un basurero como un exponente fiable de la alimentación humana cometemos un grave error, si no tenemos en cuenta los procesos que han podido mermar y hasta aumentar la información original» (Bernáldez y Bernáldez, 2004: 288).

39. En el caso concreto de Murcia se ha podido llegar un poco más allá: dada la ausencia de fuego directo sobre los huesos parece poder deducirse de nuevo que la forma más habitual de cocinarlos habría sido la cocción, en fragmentos grandes (Lluró, 1991: 97). 
de las dunas de Guardamar (Alicante), donde, entre el material recuperado, con una cronología comprendida entre los siglos IX y XI, se documentan caballo, asno y buey, seguramente no utilizados para la alimentación, ovicápridos consumidos de manera preferente en edad joven ${ }^{40}$, algo de ciervo y de conejo, un alto porcentaje de galliformes, con presencia añadida de algunas palomas, y cierta abundancia de recursos marinos, en particular de la sepia (Benito, 1989) ${ }^{41}$; o Calatrava la Vieja (Carrión de Calatrava, Ciudad Real) ${ }^{42}$, donde la supremacía habitual de la oveja (apenas se recuperaron restos de cabra) se ve complementada con una gran proliferación de conejo, una representación menor de bóvidos, cérvidos y liebre, y algo de fauna doméstica, como caballo, asno, perro, gato, y cerdo (al menos tres individuos). Por lo que se refiere a las aves, los huesos de gallina, paloma, perdiz y ánade constituyen el $80 \%{ }^{43}$ de la muestra recuperada, algunos de ellos no consumidos (Morales et al., 1989; Aguilar, 1990; Morales et al., 1992). En este mismo yacimiento ha sido documentada una cierta presencia de pescado, de mar (sardinas, jureles y alachas, llegados por vía comercial seguramente en conserva, quizás saladas, secas y ahumadas, a la manera de nuestros arenques), y de río, típico del curso medio del Guadiana (barbos, bogas y cachos) (Roselló y Morales, 1991).

En Mértola, por su parte, parece observarse una cierta diferenciación entre óvidos, cápridos y bóvidos: de los primeros se consumirían preferentemente los excedentes de individuos machos descartados para la producción ${ }^{44}$, mientras cabras y vacas se aprovecharían durante más tiempo para la obtención de leche, cría, tracción y abono, al tiempo que garantizar el reemplazo. Los galliformes, en su mayoría adultos aunque de sexo indeterminado, ocupan sólo el segundo

40. Este hecho se atribuye a la existencia de una ganadería de carácter intensivo, destinada fundamentalmente a la producción de carne (oveja, sobre todo), y leche (cabras).

41. Vid. infra para el tema de los moluscos recuperados en el yacimiento.

42. El depósito arqueofaunístico analizado, que fue recuperado en el interior de un torreón, parece haberse formado «como consecuencia de la casi segura limpieza por el contingente cristiano del interior del recinto amurallado. Esta limpieza debió incluir tanto los restos óseos prealmohades y almohades, procedentes de 'silos' o basureros, muros, etc., como fauna viva del momento» (Morales et al., 1992: 70). La toma del sitio tuvo lugar en 1212.

43. El 20\% restante lo componen cigüeña, grajilla, estornino y buitre negro, que, salvo quizás en el caso del estornino, no debieron tener relación alguna con la alimentación.

44. Estos son los datos que se deducen de la muestra taxonómica analizada, si bien parece incurrirse en una cierta contradicción por lo que se refiere a los cápridos, cuyos machos se descartan también habitualmente, destinándose a carne. Hay que pensar, pues, en otras posibilidades interpretativas, entre las que no cabe descartar su destino para la venta, aun cuando en este caso habría que preguntarse también a quién, con qué fin y por qué no se detectan en el yacimiento. lugar entre las especies de aves consumidas, cuyo ranking encabeza de corrido la perdiz. En caso de que la abundante población de conejos documentada hubiese sido criada en cautividad, la práctica totalidad de los animales de carne recuperados por el registro arqueológico habrían formado parte de la cabaña doméstica (Morales, 1993).

Otros yacimientos portugueses con valores similares son Alcácer do Sal, Santarém y Lisboa (Moreno-García y Davis, 2001). En el primero de los casos los restos estudiados se adscriben a finales del siglo IX-principios del siglo X, y sus índices de representatividad no varían mucho con relación a los ya indicados para otras poblaciones andalusíes: fundamentalmente ovicápridos (con un peso muy superior de la oveja sobre la cabra), galliformes (a las que se suman algunas perdices), conejos y liebres, en proporciones similares a las de Mértola, y en bastante menor medida bóvidos, cérvidos, y algo de pescado. La aparición de algunos restos de cerdo abogan por su consumo ocasional, por más que, de nuevo, resulte difícil determinar la identidad cultural y/o religiosa de quienes lo llevaron a su mesa. Muchas de las muestras analizadas documentaron marcas de carnicería y/o preparación previa en la cocina, y un porcentaje significativo de ellas, con independencia de la especie y de su tamaño, fueron roídas por gatos o perros, lo que permite identificarlas como restos o desechos de comida y de mesa. Entre las aves se señala con seguridad la presencia de gallinas ponedoras.

En el convento de San Francisco de Santárem los huesos analizados proceden de tres silos fechados entre finales del siglo X e inicios del XI y testimonian el consabido dominio de los ovicápridos, en su mayoría de edades inferiores a los dos años, seguidos en esta ocasión por los lagomorfos, los bóvidos, los cérvidos, las aves y el pescado ${ }^{45}$, con huellas de procesado y de roído (también por parte de ratas) similares a las detectadas en Alcácer do Sal. Las gallinas ponedoras de Santarém son, sin embargo, de mayor tamaño, lo que se interpreta como una mejora de la raza, o la pertenencia a razas diferentes. Finalmente, los datos de Lisboa son menos significativos, pero apuntan en la misma dirección: ovicápridos, con una proporción de 3:1 en relación con los bóvidos, lagomorfos, galliformes, y una presencia testimonial del cerdo.

Otro conjunto lusitano del que disponemos de información bien contrastada para toda la etapa islámica es la ciudad de Silves, donde con pequeños matices locales (por ejemplo, la relativa abundancia de moluscos), las tendencias en cuanto a la representación en el registro arqueofaunístico de especies animales se mantienen. Más allá de que pudiera obedecer a la introducción de alguna nueva raza, la detección por

45. La presencia de este último, en forma de mújoles, barbos, carpas y esturiones, por orden de representatividad, resulta bastante más significativa de lo habitual, lo que parece asignarle un lugar importante en la dieta. 
parte de S. Davis de un aumento de talla en la cabaña ganadera de óvidos con relación a la época romana se ha interpretado como testimonio claro de una especialización en la cría, destinada entre otros objetivos a la producción de carne (Antunes, 1991; Davis et al., 2008; Davis et al., 2013, estos dos últimos con numerosa bibliografía específica anterior, relativa sobre todo a Portugal).

Por último, y para no alargar mucho más esta relación, conviene destacar el trabajo realizado hace unos años sobre el castillo de Albarracín, en el que combinando los estudios arqueozoológicos, territoriales y etnoarqueológicos ha sido posible llegar a derivaciones históricas de gran interés, relacionadas por ejemplo con la trashumancia (Moreno García, 2001).

\section{A MODO DE SÍNTESIS}

«Si el paciente puede ser tratado con dieta, deben evitarse los medicamentos simples y especialmente las asociaciones de medicamentos» (Abu Bakr b. M. b. Zakariya al-Razi, Rhazes; $c f r$. Huetos y Salas-Salvadó, 2005: 224).

La cita incluida más arriba resume a la perfección el sentir de los médicos y tratadistas islámicos sobre el papel de la dieta en la salud del individuo, actitud heredada de sus precedentes clásicos y orientales (Hipócrates, Galeno, Avicena...) que ellos racionalizan y subliman eventualmente. Sabios y dietistas andalusíes tuvieron la plena convicción de que el buen funcionamiento del organismo, incluso el humor, depende por completo de la alimentación; de ahí la necesidad de tomar una dieta equilibrada, en la que los diferentes tipos de productos que componen la ingesta tengan una presencia adecuada y se combinen entre sí de forma certera a lo largo del año (porque cada estación aporta productos diversos, al tiempo que cambian los condicionantes medioambientales y los requerimientos del cuerpo), en cantidad y en calidad, a fin de potenciar su sabor y de exaltar sus propiedades. «El comer en exceso es como un veneno mortal para cualquier tipo de constitución corporal, y es la principal causa de todas las enfermedades», dejó dicho Maimónides ( $c f r$. Huetos y Salas-Salvadó, 2005: 232). Otra cosa es que su nivel de conocimientos les hiciera errar a veces en sus recomendaciones, pero en líneas generales supieron entender que dieta y salud van indisolublemente unidas, sentando las bases de la moderna bromatología.

Cuando llegan a la península Ibérica los musulmanes encuentran una agricultura disminuida, que saben relanzar enseguida mediante una nueva distribución de las tierras, una nueva gestión del agua, acostumbrados como estaban a racionarla en sus países de origen, mucho más escasos en ella, y una intensificación de la producción que favorece el abastecimiento regular de los zocos. Unen a ello la introducción de nuevas especies vegetales, la potenciación de otras ya existentes, una indudable sabiduría en las mezclas y ciertos refinamiento y sofisticación en las costumbres y el gusto, no sólo entre los pudientes, sino también entre las clases populares, dada su predilección por los dulces y los sabores potenciados. Tales premisas, unidas a una forma de comer variada y rica, con amplia presencia de cereales, verduras cultivadas o silvestres, legumbres, aceite de oliva, vid, carne con, en principio, la única excepción del cerdo, huevos, lácteos, frutos secos, hierbas aromáticas, especias, fruta e incluso vino, les permite fijar las bases de una alimentación inteligente, práctica, mestiza y sabia -reelabora tradiciones romanas y orientales con otras norteafricanas, mediterráneas y locales-, perfectamente adaptada al medio, el gusto y las estaciones del año, que ha perdurado en muchos de sus aspectos a lo largo de los siglos, y que genéricamente puede ponerse en relación con las bases definitorias de eso que hoy conocemos como dieta mediterránea, en sentido amplio ${ }^{46}$.

Parece, de hecho, bien probado que en al Andalus la proscripción coránica del vino no se llevó a rajatabla en ningún ámbito de la sociedad; más particularmente, justo es reconocerlo, entre las elites y los sectores acomodados de la sociedad (García Sánchez, 1995: 51; 2011a: 70; Arié, 1974-1975: 305-306). Los propios tratados de hisba se hicieron eco de esta costumbre, tratando de combatirla, y son muchas las referencias literarias que demuestran la plena normalidad con que poetas y escritores celebraban al modo báquico el consumo del vino y sus efectos embriagadores, proclives siempre a la creación y el amor ${ }^{47}$. Al-Saqundi, en su Risala, al describir el río Guadalquivir en el entorno de Sevilla, además de indicar que sus riberas están plagadas de viñas, dice textualmente: «en él no falta nunca la alegría, ni están prohibidos los instrumentos

46. Matizada, entre otras cuestiones, desde nuestra perspectiva actual, por un consumo de pescado bastante menor del que hoy consideramos ideal (según zonas y clases sociales), cierto exceso de grasas y un gusto excesivo por las especias, que como es bien sabido enmascaran los sabores.

47. Sirvan como simples ejemplos las de Ibn al-Zaqqaq: «Escancia en rueda el vino en el jardín cubierto de rocío. La sentencia de la aurora es ya ejecutiva sobre las tinieblas. El vaso de vino nos mira con [las pupilas de] sus burbujas, que sustituyen para nosotros a los ojos lánguidos. No se han ocultado las estrellas del horizonte, sino que se han trasladado de los cielos a los jardines»; estas otras de Ibn Jafaya: «La embriaguez nos acostó una tarde de placer: en ella fue blando y dulce mi pecho...; Mientras, yo ofrecía en él un vino dorado, cuyo reflejo teñía las manos de los invitados...; Sirve pronto el vino. El céfiro es lánguido y la sombra, cobijadora, erige su trémula columnata... La nube anuncia lluvia y vino [porque cuando llueve gusta beber]. Mezcla a la plata [del agua] el oro [del vino]»; o éstas de Abu Bakr ibn Baquí: «Cuando la noche arrastraba su cola de sombra, le di a beber vino oscuro y aromático, como el almizcle en polvo que se sorbe por las narices», recogidas en todos los casos por Al Saqundi en el siglo XIII (cfr. García Gómez, 1976: 99-101). 
músicos ni el beber vino, cosa que no hay nadie que repruebe o critique, mientras la borrachera no degenere en querellas y pendencias. Algunos gobernadores, celosos en materia de religión, intentaron suprimir tal estado de cosas, pero no pudieron lograrlo» (cfr. García Gómez, 1976: 120). También recuerda que al Hakam II, por consejo de los ulemas, intentó prohibir la producción de vino arrancando las viñas, pero desistió cuando comprobó que se fabricaba de otro tipo de plantas.

A la abundante información aportada por las fuentes escritas sobre la alimentación y los modos de comer en al-Andalus, se suma actualmente la derivada de los hallazgos arqueológicos, incrementada de manera considerable en los últimos años debido a la proliferación de análisis de paleofauna realizados en muchos de los yacimientos andalusíes excavados. A partir de ellos es posible confirmar-como ya indican de manera recurrente aquéllas, en particular los tratados de hisba y los tratados médicos, bromatológicos o de cocina (García Sánchez, 1986: 239 ss.)- que la dieta cárnica de los andalusíes se basó en un consumo preferente de ovicápridos (los óvidos por encima de los cápridos, si bien éstos fueron más accesibles al parecer para las clases populares), criados fundamentalmente para carne, a tenor de las edades de sacrificio, con frecuencia en el primer año de vida y casi siempre por debajo de los tres años ${ }^{48}$, en particular machos. Tal extremo es ratificado sin matices por los análisis arqueofaunísti$\cos$, que parecen apuntar a una clara preferencia por las carnes tiernas y un consumo menos minoritario del que siempre se ha supuesto.

A los ovicápridos les siguen por orden de importancia las aves, sobre todo gallinas, gallos y pollos, lo que parece contradecir algunos textos de la época que señalan a estos animales como manjar exclusivo de mesas privilegiadas, al menos por lo que se refiere a las áreas urbanas (García Sánchez, 1986: 242) 49 ; los bóvidos, menos abundantes por su posible utilización para el trabajo, si bien en algunos yacimientos como el de El Maraute (ss. X-XI) podrían incluso haber sido criados específicamente para el sacrificio; los lagomorfos,

48. Sería interesante saber qué porcentaje de los corderos y ovejas sacrificados en Al-Andalus pertenecía a la raza merina, introducida por los bereberes meriníes (de los que tomó el nombre) desde el Norte de África (García Sánchez, 1986: 238), pero no he encontrado referencias al respecto en los numerosos estudios consultados, por lo que deduzco que no resulta fácil (o posible) establecerlo.

49. «Su caldo se recomendaba como reconstituyente para las personas enfermas o convalecientes. Los sesos de gallina se prescribian para reforzar las funciones cerebrales. Los patos, gansos, palomas, perdices y hasta pequeños pájaros eran habituales en la dieta» (Huetos y Salas-Salvadó, 2005: 238). Al respecto, Díaz García, 1983: 9 ss., y más particularmente García Sánchez, 1986: 241 ss., quien analiza con detalle los diferentes y variados tipos de aves citados en las fuentes escritas de época andalusí. con predominio del conejo y la liebre salvajes, y por último la carne de caza, no siempre presente, pero entre la que ocupan lugar especial perdices y cérvidos. Como bien reflejan las fuentes escritas ${ }^{50}$, fue menos habitual incluir en la dieta pescado o moluscos, si bien hubo quien los comió, y en abundancia. Sirvan como referencias al respecto Calatrava la Vieja, donde se han recuperado restos de peces típicos del Guadiana, pero también marinos, que muy posiblemente se consumieron secados, salados y/o ahumados (Morales et al., 1989; Aguilar, 1990; Morales et al., 1992), o la rábita califal de Guardamar, donde las excavaciones de los pasados años 80 documentaron casi seis mil ejemplares de moluscos (un $82 \%$ de ellos comestibles), con un predominio de las especies terrestres y de marisma y un cierto desaprovechamiento de las típicas de arenas litorales (Rico y Martín, 1989).

Lógicamente, como es natural los matices en la alimentación dependerían siempre del nivel social y la capacidad adquisitiva de los consumidores, de las zonas geográficas y sus respectivas peculiaridades regionales, de las tradiciones y culturas locales o de origen, de las áreas de producción, e incluso de la casuística particular de cada comarca o familia. Por otra parte, es preciso tener en cuenta que el consumo circunstancial de algunas de las especies indicadas (en particular del cordero) iría ligado preferentemente a fiestas religiosas y/o celebraciones familiares, limitándose de manera habitual y cotidiana quienes tenían menos medios económicos a incluir en su dieta carnes de ave o de caza, y sobre todo despojos, muy nutritivos, mucho más baratos y de fácil acceso en los zocos.

En la práctica totalidad de los yacimientos relacionados se ha observado el uso del esquinado (sección longitudinal de la canal dividiéndola por la médula espinal) en el despiece de las canales, así como algunas huellas de trabajos especializados en el descuartizamiento de los animales, particularmente de tallas grandes, caso de los bóvidos, que sugieren con claridad la intervención de carniceros profesionales y la compraventa de esas mismas carnes en los zocos; algo que, como es lógico, afecta de manera especial a los núcleos urbanos. Por último, a tenor de los resultados obtenidos en Medina Azahara, no parece que las diferencias de dieta y de alimentación entre las clases elevadas y las populares radicaran en las especies animales consumidas -más allá de pequeños matices regionales, o la mayor o menor abundancia y/o consumo de caza y de pescado de mar o de río-, sino en los

50. De los dos únicos tratados de cocina de época andalusí que nos han llegado, ambos del siglo XIII, en el de cocina hispano-magrebí, que contiene aproximadamente 500 recetas, sólo 20 de ellas incluyen el pescado, mientras unas 300 incorporan la carne, de ave, conejo, cordero y carnero, en ese orden. El otro (Fadala), propiamente andalusí, incluye 400 recetas, de las cuales unas 160 tienen por base la carne (García Sánchez, 1995: 56) 
ingredientes utilizados, la elaboración de los platos, su presentación y, por supuesto, la forma de servirlos.

Son datos de enorme interés, que ilustran cual foto fija las costumbres culinarias y la base dietética de al menos una parte de quienes habitaron un día los respectivos centros urbanos analizados. Conviene, en cualquier caso, tener siempre en cuenta el carácter relativo de este tipo de muestras, dada su escasa representatividad con relación a la globalidad de las ciudades o los yacimientos en los que han sido recuperados. Sería necesario conocer valores relativos a alguno de tales asentamientos completos -en el espacio, y también en toda su fase de ocupación islámica-para alcanzar una semblanza mínima de cómo se alimentó su población, y si es posible establecer matices por épocas, barrios, sectores sociales, religión o cualquier otro aspecto de la misma. Habrá, pues, que estar muy atentos en los próximos años a los aportes de las ciencias biológicas, que poco a poco se van imponiendo como auxiliares en la interpretación arqueológica, por su importancia determinante para eso que se viene dando en llamar historia de la alimentación, como algo estructural que resulta indicativo de las diversas sociedades, de su evolución en el tiempo y de sus procesos de adaptación. Es el caso de la Paleobotánica, fundamental para reconstruir el paisaje antiguo en el que se movieron estas gentes, pero también de la Bioestratinomía, y más particularmente de la Arqueozoología, vitales para detectar y definir los patrones de consumo a partir de los restos óseos recuperados en fosas, basureros, contextos domésticos o de cualquier tipo.

Con todo, si bien es evidente que en cualquiera de los casos fueron los habitantes del sitio «quienes decidieron la presencia de las especies (mediante selección cinegética o doméstica), el uso de las diferentes porciones anatómicas de éstas (dependiendo del tipo de descuartizamiento del animal, alteraciones por cocciones, etc), y hasta el lugar de la ubicación de los restos (basureros)» (Cereijo et al., 1991: 143), con las implicaciones que ello acarrea, es importante considerar al respecto de lo anterior una cuestión capaz de relativizar por sí misma cuanto se ha expresado más arriba: E. Bernáldez y M. Bernáldez, entre otros autores, consideran errónea la práctica habitual de identificar automáticamente la proporción cuantitativa de restos recuperados con la frecuencia del consumo, que no suele tener en cuenta los factores culturales, químicos y fisiogénicos habituales en la conformación de los basureros y muladares; los procesos de despiece en mataderos u hogares; la reutilización de algunos huesos a nivel industrial o artesanal; la limitada representatividad de la muestra analizada en relación con la globalidad original, que pudo alcanzar varios miles de individuos, o las características del basurero o depósito, a su vez representativos de sólo una porción o sector de la población en un tiempo determinado; el uso diferencial o conjunto de esos mismos muladares por varios grupos sociales y/o religiosos, o las dinámicas que suelen acompañar a la desaparición física de las especies más pequeñas, incluida la intervención de otros animales en la conformación del depósito (Bernáldez y Bernáldez 2002: 430 ss.; 2004: 288 ss.) $)^{51}$. Y es que hablamos de residuos, que ya en su momento constituyeron sólo una parte de la muestra, y que nos han llegado por mor de una larga serie de procesos deposicionales y post-deposicionales (de forma, pues, un tanto aleatoria), en representación porcentualmente indeterminable de la misma ${ }^{52}$. Eso, sin tener en cuenta las condiciones de su excavación, que no siempre utiliza la metodología correcta, ni recupera la globalidad de los restos, acumulando así nuevas pérdidas. Son, por tanto, en cualquiera de los casos, muestras insuficientes para recrear en su plena dimensión la paleoecología, la cabaña ganadera, la economía o los hábitos alimenticios de tales poblaciones, que requieren de cierta cautela interpretativa a la hora de poner en relación el registro paleo-orgánico con la lectura estrictamente arqueológica.

Estos aspectos, sin duda de enorme interés, introducen un componente obligado de prudencia y humildad extraordinariamente trascendentes en la valoración de los análisis tafonómicos al uso, en su parcialidad-también, en su utilidad-, y en las derivaciones históricas de los mismos. Así ocurre, verbigracia, con los huesos de vaca, poco frecuentes por lo general pero también muy demandados por la industria ósea, lo que posiblemente influyó en sus porcentajes de conservación, o con los individuos jóvenes, mucho mejor conservados en basureros controlados, en los que por regla general fueron enterrados sin solución de continuidad, que cuando quedaron a la intemperie y sometidos a las diversas categorías de depredadores. De acuerdo con ello, es obvio que sólo podremos reconstruir la historia de la alimentación de los pobladores que generaron los desechos analizados de manera sesgada y parcial; pero dicha limitación no puede bajo ningún concepto disuadirnos de intentarlo.

\section{REFERENCIAS}

Aguilar Baltar, A.L. (1990). Calatrava la Vieja: primer informe sobre la fauna de vertebrados recuperada en el yacimiento almohade. Segunda parte: aves. Boletín de Arqueología Medieval, 4, 285-309.

Agüera, E., Vivo, J., Monterde, J.G., Mir, F.; Robina, A., Galisteo, A.M.,... y Córdoba, R. (2005). Identificación del material óseo perteneciente a las canalizaciones de la Casa

51. Es lo que otros autores llaman tafocenosis, «o proceso de pérdida de información ósea desde la deposición de los restos hasta su extracción arqueológica y posterior estudio» (Benito, 1989: 153 ss.).

52. «En realidad, estamos contando la odisea de un muerto del que nos llegan algunos huesos procedentes de la actividad consumidora de un carnívoro que aprovecha las sobras como un carroñero, el hombre» (Bernáldez, 2009: 21) 
de Yafar y de las viviendas de servicio de Madinat Al-Zahra. Meridies. Revista de Historia Medieval, VII, 39-58.

Antunes, M.T. (1991). Restos de animais no Castelo de Silves (séculos VIII-X). Contribução para o conhecimiento da alimentação em contexto islâmico. Estudos Orientais, 2, 41-74.

Aran Herrera, A. (2012). La población de 'Marroquíes Bajos': Reconstrucción de la vida biológica, social y cultural de la necrópolis musulmana de Jaén. Estrat Critic, 6, 68-84.

Arié, R. (1974-1975). Remarques sur l'alimentation des musulmans d'Espagne au cours du bas moyen âge. Cuadernos de Estudios Medievales y Ciencias y Técnicas Historiográficas, 2-3, 299-312.

Barceló, M. (1989), El diseño de espacios irrigados en alAndalus: Un enunciado de principios generales. En L. Cara (Ed.). I Coloquio de Historia y Medio Físico. El agua en zonas áridas. Arqueología e historia, Vol. I (pp. XV-XLV). Almería: Instituto de Estudios Almerienses.

Barceló, M. (1995). De la congruencia y la homogeneidad de los espacios hidráulicos en Al-Andalus. En El agua en la agricultura de al-Andalus (pp. 25-39). Granada: Lunwerg.

Barceló, M. (2004). Los Banû Ruayn en al-Andalus. Una memoria singular y persistente. Granada: Universidad de Granada.

Barceló, M. y Labarta, A. (1988). Le sucre en Espagne. Journal d'Agriculture Traditionnelle et de Botanique Appliquée, $X X X V, 175-193$.

Barceló, M., Kirchner, H., Martí, R. y Torres, J.M. (1998). The design of irrigation systems in al-Andalus. The cases of Guajar Faragüit (Los Guájares, Granada, Spain) and Castellitx, Aubenya and Biniatró (Balearic Islands). Barcelona: Universitat Autònoma de Barcelona.

Benito, M. (1989). La fauna de la rábita califal de las dunas de Guardamar. En R. Azuar (Coord.). La rábita califal de las dunas de Guardamar (Alicante). Cerámica. Epigrafía. Fauna. Malacofauna (pp. 153-161). Alicante: Diputación Provincia-Museo Arqueológico de Alicante.

Bernáldez, E. (2009). Basureros arqueológicos: 8000 años de historia nos esperan. En J.M. Hita, J. Suárez y F. Villada (Coords.). Comer en Ceuta en el s. XIV. La alimentación durante la época marini (pp. 17-37). Ceuta: Comunidad Autónoma de Ceuta.

Bernáldez, E. y Bernáldez, M. (1998). Muladares y basureros de ayer, historia de hoy. Restos orgánicos en los extramuros de la ciudad de Sevilla. PHBoletín, 22, 29-44.

Bernáldez, E. y Bernáldez, M. (2002). El subsuelo de la Catedral de los siglos XI a XVIII: de vertedero a cantera. En A. Jiménez Martín (Ed.). Magna Hispalensis (I). Recuperación de la Aljama Almohade (pp. 429-472). Sevilla: Aula Hernán Ruiz, Cabildo Metropolitano.

Bernáldez, E. y Bernáldez, M (2004). El vertedero islámico del Hospital de las Cinco Llagas. Historias Orgánicas en la Basura. En Arqueología y Rehabilitación en el Parlamento de Andalucía. Investigaciones arqueológicas en el antiguo
Hospital de las Cinco Llagas de Sevilla (pp. 288-318). Sevilla: Parlamento de Andalucía.

Bolens, L. (1981). Agronomes andalous du Moyen-Âge. Genève: Universitè de Genève. Faculté des Lettres.

Bolens, L. (1989). L'étonnante apparition du couscous en Andalousie médiévale (XIII siècle): essai d'interprétation historique. Mélanges d'histoire économique offerts en l'honneur du Professeur Anne-Marie Piuz (pp. 61-70). Genève: Département d'Histoire Économique.

Bolens, L. (1991). La cocina andaluza, un arte de vivir. Siglos XI-XIII. Madrid: EDAF.

Cara, L. y Rodríguez, J.M. (1989). El ámbito económico del pastoralismo andalusí. Grandes aljibes ganaderos en la provincia de Almería. En L. Cara (Coord.). I Coloquio de Historia y Medio Físico. El agua en zonas áridas. Arqueología e historia, Vol. II (pp. 633-653). Almería: Instituto de Estúdios Almerienses.

Cardoso, J. L. (1993). Contribução para o conhecimento da alimentação em contexto islâmico: estudo dos restos mamalógicos e malacológicos das Mesas do Castelinho (Almodôvar). Arqueologia Medieval, 2, 103-107.

Carmona Ávila, R. (2010). La ocupación medieval andalusí del Cerro de la Cruz. En I. Muñiz y F. Quesada (Eds.). Un drama en tres actos: dos milenios de ocupación humana en el Cerro de la Cruz (Almedinilla, Córdoba) (pp. 109-123). Almedinilla: Ayuntamiento de Almedinilla.

Casal, M.T. (2008), Características generales del urbanismo cordobés de la primera etapa emiral: el Arrabal de $\breve{a} a$ qunda. Anejos de Anales de Arqueología Cordobesa, 1, 109-134.

Casal, M.T., Martínez, R.M. y Araque, M.M. (2010). Estudio de los vertederos domésticos del arrabal de Šaqunda: ganadería, alimentación y usos derivados (750- 818 d.C.) (Córdoba). Anejos de Anales de Arqueología Cordobesa, 2, $143-182$.

Castro Martínez, T. (1996). La alimentación en las crónicas castellanas bajomedievales. Granada: Universidad de Granada.

Cereijo, M.Á., Herranz, M.Á. y Patón, D. (1991). Caracterización de arqueofaunas medievales a partir de análisis multivariantes. Complutum, 1, 143-151.

Davis, S.J.M., Gonçalves, M.J. y Gabriel, S. (2008). Animal remains from a Moslem period (12 th/13 th century AD) lixeira (garbage dump) in Silves, Algarve, Portugal. Revista Portuguesa de Arqueologia, 11, 183-258.

Davis, S.J.M., Svensson, E.M., Albarella, U., Detry, C., Götherström, A., Pires, A. y Ginja, C. (2013). Evidencia de mejoras de ovino y vacuno durante época andalusí y cristiana en Portugal a partir del análisis zooarqueológico y de ADN antiguo. Debates de Arqueología Medieval, 3, 241-287.

Díaz García, A. (1979-1980). Un tratado nazarí sobre alimentos: Al-Kalâm alà l-agdiya de al-Arbûlî. Edición, traducción y estudio con Glosario (I). Cuadernos de Estudios Medievales, VII-VIII, 5-37. 
Díaz García, A. (1983). Un tratado nazarí sobre alimentos: Al-Kalâm alà l-agdiya de al-Arbûlî. Edición, traducción y estudio, con glosarios (II). Cuadernos de Estudios Medievales, $X-X I, 5-91$.

Díaz García, A. y Malpica, A. (1988). Motril y el azúcar en época medieval. El cultivo de la caña de azúcar en la costa granadina en época medieval. Documento árabe sobre el aduana del açucar de Motril. Granada: Ayuntamiento de Motril-Diputación Provincial de Granada-Azucarera del Guadalfeo.

Dozy, R. (1873). Le calendrier de Cordoue de l'année 961 texte arabe et ancienne traduction latine. Leyde: E.J. Brill.

El Hour, R. (2005). La alimentación de los sufíes-santos en las fuentes hagiográficas magrebíes. El caso de Marruecos. En M. Marín y C. de la Puente (Eds.). El banquete de las palabras: la alimentación en los textos árabes (pp. 207-235). Madrid: CSIC

Ferhat, H. (1997). Frugalité soufie et banquets de zaouyas: l'éclairage des sources hagiographiques. Médiévales, 33, 69-79.

Ferre Cano, D. y García Sánchez, E. (1992). Alimentos y medicamentos en las tres versiones medievales de El régimen de salud de Maimónides. En E. García Sánchez, E. (Ed.). Ciencias de la naturaleza en Al-Andalus: textos y estudios. II (pp. 23-96). Granada: CSIC.

García García, M. (2011). Aportaciones de la Arqueobiología para el conocimiento de la Edad Media en la Península Ibérica. Estrat Critic, 5(2), 445-453.

García García, M. (2012). Estudio zooarqueológico y ganadería en al-Andalus. Enunciado de necesidades y de posibilidades. Arqueología Medieval. Recuperado de: http://www. arqueologiamedieval.com/articulos/136/estudio-zooarqueologico-y-ganaderia-en-al-andalus-enunciado-de-necesidades-y-posibilidades

García García, M. (2014). Zooarchaeological analysis of the Islamic medieval town of Ilbīrah, Granada (south-east Iberia). Assemblage PZAF (2014), 86-100.

García García, M. (2016). Some remarks on the provision of animal products to urban centres in medieval Islamic Iberia: The cases of Madinat Ilbirah (Granada) and Cercadilla (Cordova). Quaternary International. DOI: http://dx.doi. org/10.1016/j.quaint.2016.06.021

García García, M. y Moreno García, M. (s.f.). De huertas y rebaños: perspectivas históricas y ecológicas sobre el papel de la ganadería en la agricultura andalusí. SEHA3/Seminario; original disponible en Internet.

García Gómez, E. (1976). Elogio del Islam español (Risala fi fadl Al-Andalus), por Al-Saqundi. En Andalucía contra Berbería. Reedición de traducciones de Ben Hayyan, Saqundi y Ben Al-Jatib (pp. 43-141). Barcelona: Universidad de Barcelona.

García Sánchez, E. (1980). Ibn al-Azraq: Urzûya sobre ciertas preferencias gastronómicas de los granadinos. En J. Bosch y W. Hoenerbach (Dirs.). Andalucía Islámica. Textos y Estudios I (pp. 143-162). Granada: Universidad de Granada.
García Sánchez, E. (1992). La agronomía en al-Andalus. En El legado científico de al-Andalus (pp. 145-155). Barcelona: El legado andalusí.

García Sánchez, E. (1983). La alimentación en la Andalucía islámica. Estudio histórico y Bromatológico: I. Cereales y leguminosas. Andalucía Islámica. Textos y Estudios II-III (pp. 139-176). Granada: Universidad de Granada.

García Sánchez, E. (1986). La alimentación en la Andalucía islámica. Estudio histórico y bromatológico. II: carne, huevos, leche y productos lácteos. Andalucía Islámica. Textos y Estudios IV-V (1983-1986) (pp. 237-278). Granada: Universidad de Granada.

García Sánchez, E. (1988). Los cultivos de al-Andalus y su influencia en la alimentación. En Aragón vive su historia: Actas de las II Jornadas Internacionales de Cultura Islámi$c a$ (pp. 183-192). Teruel: Ediciones Al-Fadila.

García Sánchez, E. (1989). El azúcar en la alimentación de los andalusíes. En La caña de azúcar en tiempos de los Grandes Descubrimientos (1450-1550). Actas del primer Seminario Internacional (pp. 209-231). Granada: Motril. Casa de la Palma.

García Sánchez, E. (1995). La gastronomía andalusí. En V. Salvatierra (Ed.). El zoco: vida económica y artes tradicionales en al-Andalus y Marruecos (pp. 49-57). Madrid: Lunwerg.

García Sánchez, E. (1996). La alimentación popular urbana en al-Andalus. Arqueología Medieval, 14, 219-236.

García Sánchez, E. (1997a). La tríada mediterránea en alAndalus. En C. San Martín y M. Ramos (Coords.). Con pan, aceite y vino La tríada mediterránea a través de la Historia (pp. 97-127). Granada: Grupo Editorial Universitario.

García Sánchez, E. (1997b). Especies panificables y su forma de consumo en la España musulmana. Actas Etnobotánica, 92, 489-495.

García Sánchez, E. (2002). El sabor de lo dulce en la gastronomía andalusí. En F. Nuez (Ed.). La herencia árabe en la agricultura y el bienestar de Occidente (pp. 165-204). Valencia: Servicio de Publicaciones de la Universidad Politécnica de Valencia.

García Sánchez, E. (2004). Especias y condimentos en la sociedad andalusí: prácticas culinarias y aplicaciones dietéticas. En A. Garrido (Ed.). El sabor del sabor: hierbas aromáticas, condimentos y especias (pp. 71-96). Córdoba: Servicio de Publicaciones Universidad de Córdoba.

García Sánchez, E. (2005). Comida de enfermos, dieta de sanos: procesos culinarios y hábitos alimenticios en los textos médicos andalusíes. En M. Marín y C. de la Puente, C. (Eds.). El banquete de las palabras: la alimentación en los textos árabes (pp. 57-87). Madrid: CSIC.

García Sánchez, E. (2007). Aceitunas y aceite de oliva en la tradición culinaria andalusí. En Aavv, Tierras del olivo (pp. 136-147). Sevilla: El Legado andalusí.

García Sánchez, E. (2011a). Alimentación y paisajes agrícolas en al-Andalus. Revista Ambienta, 95, 64-76. 
García Sánchez, E. (2011b). La alimentación de los andalusíes: entre las normas médicas y la vida cotidiana. En El saber en Al-Andalus. Textos y Estudios, V. Homenaje a la Profra. Dña. Carmen Ruiz Bravo-Villasante (pp. 121-134). Sevilla: Secretariado de Publicaciones Universidad de Sevilla.

Garrido, L., Hernández, S. y Zambrana, J.F. (2007). Historia del aceite de oliva y el olivar. En AA.VV. Tierras del olivo (pp. 260-271). Sevilla: El Legado andalusí.

Glick, F. (1992a). Hydraulic technology in Al.Andalus. En S. K. Jayyusi (Ed.). The legacy of Muslim Spain (pp. 974986). Leiden: E.J. Brill.

Glick, F. (1992b), El sentido arqueológico de las instituciones hidráulicas. Regadío bereber y regadío español. En Aragón vive su historia: Actas de las II Jornadas Internacionales de Cultura Islámica (pp. 165-171). Teruel: Ediciones Al-Fadila.

Glick, T. F. y Kirchner, H. (2000). Hydraulic systems and technologies of Islamic Spain: History and archaeology. En P. Squatriti (Ed.). Working with water in Medieval Europe. Technology and Resource-Use (pp. 267-329). Leiden-London-Köln: E.J. Brill.

González Turmo, I. y Mataix, J. (2008). Alimentación y Dieta Mediterránea. Sevilla: Consejería de Agricultura y Pesca. Junta de Andalucía.

Grau, I. (2009). Ganadería en la Alta Edad Media. Estudio comparativo de los yacimientos alaveses de Zornoztegi, Zaballa y Salvatierra-Agurain. Munibe (Antropología-Arkeologia), 60, 253-280.

Guede, I., Ortega, L.Á., Zuluaga, M.C., Alonso, A., Murelaga, X., Pina, M. y Gutiérrez, F.J. (2015). $\delta 13 \mathrm{C}, \delta 15 \mathrm{~N}$ y paleodieta en restos humanos de la Necrópolis Islámica Medieval de Tauste (Zaragoza). Macla. Revista de la Sociedad Española de Mineralogía, 20, 69-70.

Guichard, P. (1982). L'eau dans le monde musulman medieval. En J. Métral y F. Métral (Eds.). L'Homme et l'eau en Méditerranée et au Proche Orient. II. Aménagements hydrauliques, État et législation. Séminaire de recherche 1980-1981 (pp. 117-124). Lyon: Presses Universitaires de Lyon.

Guinot, E. (2007). La construcció d'un paisatge medieval irrigat: l'horta de la ciutat de València. En F. Sabaté (Ed.). Natura i desenvolupament. El medi ambient a l'Edat Mitjana (pp. 191-220). Lleida: Pagès Editors.

Hernández, F. (1993). Los restos de aves del yacimiento medieval de Mértola. Arqueología Medieval, 3, 273-276.

Hita, J.M., Suárez, J. y Villada, F. (Coords.). (2009a). Comer en Ceuta en el s. XIV. La alimentación durante la época mariní. Ceuta: Comunidad Autónoma de Ceuta.

Hita, J.M., Suárez, J. y Villada, F. (2009b). La alimentación en la Ceuta mariní: una aproximación a su problemática. En J.M. Hita, J. Suárez y F. Villada (Coords.). Comer en Ceuta en el s. XIV. La alimentación durante la época mariní (pp. 102-151). Ceuta: Comunidad Autónoma de Ceuta.
Huetos, M.D. y Salas-Salvadó, J. (2005). Alimentación, dietética y nutrición en al-Andalus. En J. Salas-Salvadó, P. García-Lorda y J.M. Sánchez, J.M. (Eds.). La alimentación y la nutrición a través de la historia (pp. 217-246). Barcelona: Editorial Glosa.

Ibn Zuhr, Abd al-Malik b. Abi l'Ala' (1992). Kitab al-Agdiya (Tratado de los alimentos). Fuentes Arábico-Hispanas 4. (Edición, traducción e introducción E. García Sánchez). Madrid: Consejo Superior de Investigaciones CientíficasInstituto de Cooperación con el mundo árabe.

Kirchner, H., Virgili, A. y Antolín, F. (2014). Un espacio de cultivo urbano en al-Andalus: Madîna Turțîša (Tortosa) antes de 1148. Historia Agraria, 62, 11-45.

Kuhne, R. (1994). Apuntes sobre el consumo de fruta en el mundo árabe medieval. En M. Marín y D. Waynes (Eds.). La alimentación en las culturas islámicas (pp. 296-308). Madrid: Cultura Hispánica.

Kuhne, R. (1996). La fruta, ¿alimento o medicamento? Reflexiones sobre la presencia de la fruta en la farmacopea medieval. Anaquel de Estudios Árabes, 7, 69-86.

León Muñoz, A. y Vaquerizo, D. (2012). Un nuevo modelo de gestión de la Arqueología Urbana en Córdoba. En J. Beltrán y O. Rodríguez (Eds.). Hispaniae Urbes. Investigaciones arqueológicas en ciudades históricas (pp. 321-361). Sevilla: Universidad de Sevilla.

Leveau, Ph. (2007). La oleicultura en la Numidia y en las Mauritanias (Argelia y Marruecos). En AA.VV. Tierras del olivo (pp. 51-65). Sevilla: El Legado andalusí.

Lluró, J.M. (1991). Los restos de fauna. En AA.VV. Una casa islámica en Murcia: estudio de su ajuar (siglo XIII) (pp. 95-97). Murcia: Centro de Estudios Árabes y Arqueológicos «Ibn Arabí».

López Guerrero, R. (2008). La cerámica emiral del arrabal de Šaqunda. Análisis cerámico del sector 6. Anejos de Anales de Arqueología Cordobesa, 1, 135-162.

López López, A. (1994). Estudio particular de las especies botánicas que se citan en el Calendario de Córdoba de 'Arīb ibn Sa‘īd. Ciencias de la Naturaleza en al-Andalus, I, 317-347.

Lozano, C. (2009). Paleobiología de los restos orgánicos desechados por la comunidad ceutí del s. XIV. En J.M. Hita, J. Suárez y F. Villada (Coords.). Comer en Ceuta en el s. XIV. La alimentación durante la época mariní (pp. 39-61). Ceuta: Comunidad Autónoma de Ceuta.

Malpica, A. (Ed.). (1995). Paisajes del azúcar, Actas del Quinto Seminario Internacional sobre la caña de azúcar. Granada: Publicaciones de la Diputación Provincial de Granada.

Malpica, A. (2011). Poblamiento, agricultura y ganadería en el reino nazarí de Granada. En A. Mattone y P.F. Simbula (Eds.). La Pastorizia Mediterranea: Storia e Diritto (secoli $X I-X X)$ (pp. 41-54). Roma: Carocci.

Malpica, A. (2012). La vida agrícola y la ganadería en alAndalus y en el reino nazarí de Granada. En R. Marín López (Ed.). Homenaje al profesor Dr. D. José Ignacio Fernández 
de Viana y Vieites (pp. 213-228). Granada: Universidad de Granada.

Malpica, A., Morère, N., Jiménez, J., García-Contreras, G. (2011). Paisajes de la sal en la Meseta castellana desde la Prehistoria a la Edad Media: el valle del Salado (Guadalajara). En M. Jiménez Puertas y G. García-Contreras (Eds.). Paisajes históricos y Arqueología medieval 4 (pp. 233-276). Granada: S. L. Alhulia.

Marín, M. (1996). Ollas y fuego: los procesos de cocción en los recetarios de al-Andalus y el Magreb. Arqueologia Medieval, 4, 165-174.

Marín, M. (2005). Los recetarios árabes clásicos: ¿documentos históricos? En M. Marín y C. de la Puente, C. (Eds.). El banquete de las palabras: la alimentación en los textos árabes (pp. 29-56). Madrid: CSIC.

Martínez Enamorado, V. (2007). 'Aceite que viene de tierra de moros': algunos datos sobre la comercialización del aceite de oliva andalusí. En AA.VV. Tierras del olivo (pp. 168-175). Sevilla: El Legado andalusí.

Martínez Enamorado, V. (2009). Paladares de príncipes, recetas cortesanas, comidas de campesinos. Valoraciones en torno a La alimentación de los andalusíes. En J.M. Hita, J. Suárez y F. Villada (Coords.). Comer en Ceuta en el s. XIV. La alimentación durante la época marini (pp. 63-99). Ceuta: Comunidad Autónoma de Ceuta.

Martínez Sánchez, R. (2010). Análisis arqueozoológico de la fase ibérica y medieval del Cerro de la Cruz. Campañas de 2006-2008. Oikos. Cuadernos Monográficos del Ecomuseo del río Caicena, 2, 141-150.

Martínez Sánchez, R. (2012). Arqueozoología en el Emirato. Una aproximación desde la capital política y los territorios rebeldes (756- 929 d C). En J. Cascalheira y C. Gonçalves (Eds.). Actas das IV Jornadas de Jovens em Investigação Arqueológica - JIA 2011, Vol. I (pp. 305-311). Faro: Universidade do Algarve.

Martínez Sánchez, R. y Carmona, R. (2013). Animales en contextos arqueológicos medievales de Priego de Córdoba. Una aproximación a partir de depósitos estratificados en silos y pozos. Antiquitas, 23, 209-234.

Marwan, A. (s.f.). Kitab al-Agdiya (Tratado de los alimentos). Fuentes Arábico-Hispanas 4. Madrid (traducción E. García Sánchez): CSIC.

Morales, A. (1993). Estudio faunístico del yacimiento islámico de Mértola: los mamíferos. Arqueologia Medieval, 2, 263-271.

Morales, A., Moreno, R. y Cereijo, M. (1989). Calatrava la Vieja: primer informe sobre la fauna de vertebrados recuperada en el yacimiento almohade. Primera parte: mamíferos. Boletín de Arqueología Medieval, 2. 1988, 7-48.

Morales, A., Aguilar, A., Moreno, R., Roselló, E. y Cereijo, M.Á. (1992). Calatrava la Vieja: la fauna. En III Congreso de Arqueología Medieval Española (Oviedo, 1989), Vol. II (pp. 63-72). Oviedo: Asociación Española de Arqueología Medieval.
Moreno García, M. (2001). Sheep transhumance in medieval Spain: an ethnoarchaeological approach. En H. Buitenhuis y W. Prummel (Eds.). Animals and Man in the Past. Essays in honour of Dr. A.T. Clason emeritus professor of archaeozoology rijksuniversiteit groningen (ARC-publicatie) (pp. 251-262). Groningen: Rijksuniversiteit.

Moreno García, M. y Davis, S. (2001). Estudios de las asociaciones faunísticas recuperadas en Alcocer do Sal, convento de São Francisco, Santarém y Sé de Lisboa. En Garb. Sitios Islâmicos do Sul Peninsular (pp. 231-255). LisboaMérida: Instituto Português do Património ArquitectónicoJunta de Extremadura.

Oubahli, M. (2011). La main et le pétrin. Alimentation céréalière et pratiques culinaires en Occident musulman au Moyen Âge. Casablanca: Fundation du roi Abdul-Aziz Al Saoud pour les Éudes Islamiques et les Sciences Humaines.

Paz Martínez, M. Á. y Tusell, M. (2000). La fauna del yacimiento de Cerro Miguelico. En V. Salvatierra, J.C. Castillo y J. Aguirre, J. (Dirs.). Los asentamientos emirales de Peñaflor y Miguelico. El poblamiento hispano-musulmán de Andalucía Oriental. La campiña de Jaén (1987-1992) (pp. 152-166). Sevilla: Junta de Andalucía.

Pellat, CH. (1961). Le calendrier de Cordoue publié par $R$. Dozy. Nouvelle edition accompagnée d'une traduction française annotée. Leiden: E. J. Brill.

Pomeroy, E. y Zakrzewski, S. R. (2009). Sexual dimorphism in diaphyseak crosssectional shape in the medieval muslim population of Ecija, Spain and Anglo-Saxon great Chesterford, UK. Inter. J. Osteoarchaeol., 19, 50-65. DOI: http:// doi.org/10.1002/oa.981

Pons, A. y Tur, J. (2005). La alimentación en Bizancio. En J. Salas-Salvadó, P. García-Lorda y J.M. Sánchez (Eds.). La alimentación y la nutrición a través de la historia (pp. 159184). Barcelona: Editorial Glosa.

Retamero, F. (2009). La sombra alargada de Wittfogel. Irrigación y poder en al-Andalus. En M. Marín (Ed.). Al-Andalus/España. Historiografias en contraste. Siglos XVII-XXI (263-293). Madrid: Casa de Velázquez.

Rico, L. y Martín, C. (1989). Malacofauna. En R. Azuar (Coord.). La rábita califal de las dunas de Guardamar (Alicante). Cerámica. Epigrafía. Fauna. Malacofauna (pp. 162173). Alicante: Diputación Provincia-Museo Arqueológico de Alicante.

Riera Melis, A. (2005). Las alimentaciones cristianas en Occidente durante la Edad Media. En J. Salas-Salvadó, P. García-Lorda y J.M. Sánchez (Eds.). La alimentación y la nutrición a través de la historia (pp. 185-215). Barcelona: Editorial Glosa.

Riquelme, J. A. (1991). Estudio faunístico del yacimiento medieval de El Maraute (Torrenueva, municipio de Motril, Granada). Boletín de Arqueología Medieval, 5, 93-111.

Riquelme, J.A. (1993). Estudio faunístico del yacimiento medieval de Plaza España, Motril (Granada). Arqueologia Medieval, 2, 343-260. 
Riquelme, J.A. (1995). Estudio de los restos óseos de origen animal procedentes de 'La Lonja' en la Catedral de Granada. Antiquitas, 6, 141-150.

Rosenblum, M. (1997). La aceituna. Vida y tradiciones de un noble fruto. Barcelona: Tusquets editores.

Roselló, E. y Morales, A. (1991). Calatrava la Vieja: primer informe sobre la fauna de vertebrados recuperada en el yacimiento almohade. Tercera parte: peces. Boletín de Arqueología Medieval, 5, 113-133.

Rosselló, G. (2002). El ajuar de las casas andalusíes. Málaga: Editorial Sarria.

Sáez, P. (1991). Consideraciones sobre el cultivo del olivo en la Bética hispano-romana. Aspectos económicos y sociales. En C. González Román (Ed.). La Bética en su problemática histórica (pp. 277-297). Granada: Servicio de Publicaciones Universidad de Granada.

Sitjes, E. (2006). Inventario y tipología de sistemas hidráulicos de Al-Andalus. Arqueología Espacial, 26, 263-291.

Torres, J.M. (1988). La zooarqueología. En M. Barceló (Ed.). En Arqueología medieval. En las afueras del «medievalismo» (pp. 134-164). Barcelona: Editorial Crítica.

Torres Palomo, M.P. (2000). El pescado en la gastronomía árabe mediterránea: al-Ándalus. En A. Pérez Jiménez y G. Cruz Andreotti (Eds.). Dieta mediterránea. Comidas y hábitos alimenticios en las culturas mediterráneas (pp. 159181). Málaga: Ediciones Clásicas.

Trillo, C. (1999). El paisaje vegetal en la Granada Islámica y sus transformaciones tras la conquista castellana. Historia Agraria, 17, 131-152.

Trillo, C. (2007). El olivo en al-Andalus: tradición latina e islámica. En AA.VV. Tierras del olivo (pp. 104-115). Sevilla: El Legado andalusí.
Trillo, C. (2011). La ganadería en el reino de Granada: transformación de una actividad económica del dominio islámico al cristiano. En A. Mattone y P.F. Simbula (Eds.). La Pastorizia Mediterranea. Storia e diritto (secoli XI-XX) (pp. 629643). Roma: Carocci.

Valencia, R. (2007). El monte de los olivos. En AA.VV. Tierras del olivo (pp. 116-123). Sevilla: El Legado andalusí.

Vaquerizo, D. (2011). De especie silvestre (kótinos) a olivo sagrado (élaios). Notas sobre el cultivo del olivar, la producción, la comercialización y el consumo de aceite de oliva en el Mediterráneo antiguo. Boletín de la RAEX, XIX, 591-673.

Viguera, M.J. (2007). Olivo y aceite en textos andalusíes. En AA.VV. Tierras del olivo (pp. 148-167). Sevilla: El Legado andalusí.

Watson, A.M. (1983). Agricultural innovation in the early Islamic world: the diffusion of crops and farming techniques 700-1100. Cambridge: Cambridge University Press.

Watson, A.M. (1991). Innovaciones agrícolas en el mundo islámico. En Actas del Segundo Seminario Internacional sobre la Caña de Azúcar. La Caña de Azúcar en el Mediterráneo (pp. 7-20). Granada: Junta de Andalucía.

Watson, A.M. (1998). Innovaciones de la agricultura en los primeros tiempos del mundo islámico. Granada: Universidad de Granada.

Watson, A.M. (2007). A case of non-diffusion: the non-adoption by Muslim Spain of the open-field system of Christian Europe. Causes and consequences. En S. Cavaciocchi (Ed.). Relazioni economiche tra Europa e mondo islamico. Secc. XIII-XVIII, T. I (pp. 242-265). Firenze: Fondazione Istituto Internazionale di studi economici «F. Datini». 